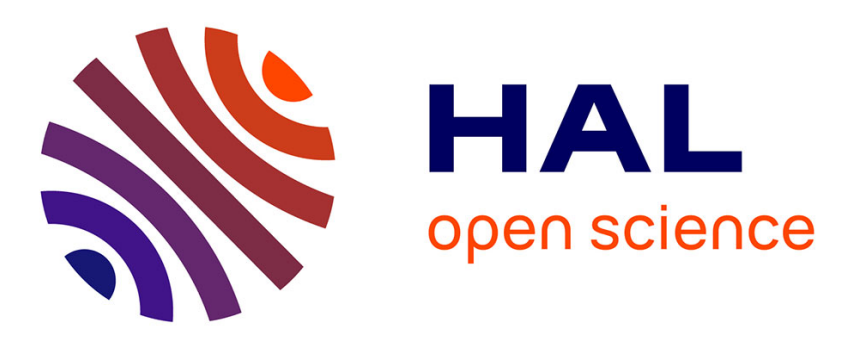

\title{
Zhoukoudian Upper Cave personal ornaments and ochre: Rediscovery and reevaluation
}

Francesco D'errico, Africa Pitarch Martí, Yi Wei, Xing Gao, Marian

Vanhaeren, Luc Doyon

\section{- To cite this version:}

Francesco D'errico, Africa Pitarch Martí, Yi Wei, Xing Gao, Marian Vanhaeren, et al.. Zhoukoudian Upper Cave personal ornaments and ochre: Rediscovery and reevaluation. Journal of Human Evolution, 2021, 161, pp.103088. 10.1016/j.jhevol.2021.103088 . hal-03445635

\section{HAL Id: hal-03445635 \\ https://hal.science/hal-03445635}

Submitted on 3 Dec 2021

HAL is a multi-disciplinary open access archive for the deposit and dissemination of scientific research documents, whether they are published or not. The documents may come from teaching and research institutions in France or abroad, or from public or private research centers.
L'archive ouverte pluridisciplinaire HAL, est destinée au dépôt et à la diffusion de documents scientifiques de niveau recherche, publiés ou non, émanant des établissements d'enseignement et de recherche français ou étrangers, des laboratoires publics ou privés. 
Zhoukoudian Upper Cave personal ornaments and ochre: Rediscovery and reevaluation Francesco d'Errico ${ }^{\mathrm{a}, \mathrm{b},{ }^{*}}$, Africa Pitarch Martía,c, Yi Weid,e, Xing Gao ${ }^{\mathrm{d}, \mathrm{f}}$, Marian Vanhaeren, Luc Doyon ${ }^{\mathrm{a}, \mathrm{g}}$

${ }^{a}$ CNRS UMR5199 PACEA, Université de Bordeaux, Pessac CEDEX, France

b SFF Centre for Early Sapiens Behaviour (SapienCE), University of Bergen, Bergen, Norway

${ }^{c}$ Departament d'Arts i Conservació-Restauració, Facultat de Belles Arts, Universitat de Barcelona, Barcelona, Spain

${ }^{\mathrm{d}}$ Centre for Excellence in Life and Paleoenvironment (CAS), Institute of Vertebrate Paleontology and Paleoanthropology, Chinese Academy of Sciences, Beijing, China

e Department of Scientific Research, Beijing Museum of Natural History, Beijing, China

${ }^{\mathrm{f}}$ University of Chinese Academy of Sciences, Beijing, China

g Institute of Cultural Heritage, Shandong University, Qingdao, China

\section{* Corresponding author.}

Email: francesco.derrico@u-bordeaux.fr (F.d'Errico) 
Zhoukoudian Upper Cave personal ornaments and ochre: Rediscovery and reevaluation

\begin{abstract}
Personal ornaments have become a key cultural proxy to investigate cognitive evolution, modern human dispersal and population dynamics. Here we reassess personal ornaments found at Zhoukoudian Upper Cave and compare them with those from other Late Paleolithic Northern Chinese sites. We reappraise the information provided by Pei Wen Chung on Upper Cave personal ornaments lost during WWII and analyze casts of 17 of them, along with two unpublished objects displayed at the Zhoukoudian Site Museum and three original perforated teeth rediscovered at the Zhoukoudian Site Museum. We apply archeozoological, technological and use-wear analyses to document variation in ornamental practices and their change throughout the site stratigraphy. Badger, fox, red deer, sika deer, marten and tiger teeth as well as carp bone, bird bone, Anadara shell, limestone beads and perforated pebble appear to have been the preferred objects used as ornaments by Upper Cave visitors. Multivariate analysis of technological data highlights a correspondence between cultural layers and perforation techniques, with radial incising being typical of layer L2 and bidirectional incising of L4. The three rediscovered badger canines display features suggesting they were sewed on clothing rather than suspended from necklaces or bracelets. Elemental (SEM-EDS) and mineralogical ( $\mu$ Raman) analyses of red residues adhering to the rediscovered teeth indicate these objects were originally coated with ochre and identify variations that match differences in technology. The two ornaments exhibited at the Zhoukoudian Site Museum are ancient teeth that were recently perforated and should be excluded from the Upper Cave assemblage. A seriation of Late
\end{abstract}


Paleolithic ornaments found at Northern Chinese sites identifies a clear-cut difference in preferred ornament types between western and eastern sites, interpreted as reflecting two longlasting traditions in garment symbolic codes.

Keywords: Symbolism; East Asia; Upper Paleolithic; Homo sapiens; Fake identification; Residue analysis

\section{Introduction}

The last two decades have radically changed our understanding of the origin and evolution of technologies used by humans to modify their appearance and transform their bodies into means of communication. Evidence attesting to a very ancient use of mineral pigments in Africa and Europe indicates that body painting and associated practices may date back to at least 300 ka (Roebroeks et al., 2012; de Lumley et al., 2016; Watts et al., 2016; Brooks et al., 2018). A growing number of African and Levantine sites has revealed that the origin of ornament manufacture and use should be pushed back to at least $120 \mathrm{ka}$ (Bouzouggar et al., 2007; Steele et al., 2019; Vanhaeren et al., 2019; Bar-Yosef Mayer et al., 2020; d'Errico et al., 2020). Compared to the earliest occurrences of pigment and personal ornament in Africa, Levant and Europe, the evidence from East Asia is relatively recent (Song and Shi, 2013; Wei et al., 2016, 2017; Pitarch Martí et al., 2017; Langley et al., 2019, 2020; Li et al., 2020). For most of the last century, Zhoukoudian Upper Cave Upper Cave (UC), which is the focus of the present work, has represented the only Paleolithic site providing substantial information on early personal ornamentation and ochre use in East Asia (e.g., Reynolds, 1991; Clark et al., 1992; Wu, 2004; 
Norton and Jin, 2009). The discovery of personal ornaments at Xiaogushan, Liaoning Province, (Huang et al., 1986), has not dramatically changed this picture due to the relatively small number of objects found at this site and uncertainties surrounding the chronology of its occupations.

Recent discoveries from Asia document in unprecedented ways the first occurrences of body ornamentation in various sub-regions of this vast continent. They reveal a striking diversity and complexity of practices and provide initial insights into long-term regional trends (Pitulko et al., 2012; Song and Shi, 2013; Stiner et al., 2013; Wei et al., 2016, 2017; Pitarch Martí et al., 2017; Shidrang, 2018; Bosch et al., 2019; Langley et al., 2019, 2020; Bar-Yosef Mayer et al., 2020; Shunkov et al., 2020). However, the number of sites we can rely upon to document the origin of this key phenomenon in Asia remains limited, and those with sufficient material to characterize the practices involved in personal ornaments manufacture and use are even rarer. Only a handful of sites have yielded personal ornaments within stratigraphic sequences covering a long timespan, allowing to document changes in body decoration through time (Langley et al., 2016, 2020). Consequently, we are still far from being able to explore regional variability of ornaments through multivariate analyses at a continental scale, as it was done for the early Upper Paleolithic and the Mesolithic-Neolithic transition in Europe (Vanhaeren and d'Errico, 2006; d'Errico and Vanhaeren, 2015; Rigaud et al., 2015, 2018), and for Australian Aboriginal ornaments (McAdam, 2008; Balme and O'Connor, 2019).

In Asia, the origin of personal ornaments is a research subject closely intertwined with that of modern human dispersal out of Africa. The first reason for such a connection certainly lies in the fact that ornaments and ochre use were traditionally regarded, before the African discoveries, as a distinctive feature of biologically and culturally modern populations and the alleged adaptive advantages they would have granted to these human groups during their 
dispersal (Mellars, 2006a, b; Liu et al., 2015; Dennell et al., 2020). Second, this association is supported by the fact that, unlike in Europe, Asian archaeological contexts in which ornaments and ochre co-occur at sites occupied by archaic populations, such as Neanderthals and Denisovans, are very rare (Petraglia et al., 2007; Bar-Yosef Mayer et al., 2020; Shunkov et al., 2020). In addition, most of the earliest known occurrences of these novel cultural traits date back to ca. $45-40 \mathrm{ka}$, an age fully consistent with the attested presence of modern humans in many regions of East Asia and Wallacea (Kealy et al., 2016; Bergström et al., 2021). In North China, for instance, the direct dating of modern human remains from Tianyuan Cave (Shang et al., 2007), the locality 27 of the Zhoukoudian site complex, and presence of hæmatite at this site (Tong et al., 2004), suggest a link between modern human dispersal and symbolic material culture around 42-39 ka. Third, recent chronological reappraisal of human remains from key Southern Chinese sites (Sun et al., 2021) previously interpreted as early evidence for modern human dispersal between ca. 120-80 ka (Shen et al., 2013; Bae et al., 2014; Liu et al., 2015; Dennell et al., 2020), give supplementary strength to the view that items of personal ornamentation and ochre use can be considered as proxies for modern human dispersal in this region. Direct AMS dating and OSL and U-Th ages for sediment and flowstones from these sites have considerably lowered the age of these human remains and make current evidence fully compatible with a 'late' human arrival, i.e., 50-45 ka, in this region (Curnoe et al., 2021; Sun et al., 2021; see, however, Higham and Douka, 2021; Martinón-Torres et al., 2021).

Whether or not the link between modern human dispersal and complex symbolic material culture is confirmed by future studies, the mere presence of personal ornaments and pigment does not, in and of itself, shed light on past population structure and cultural trajectories. Given the key role these cultural items play in signaling distinct ethnic and social affiliations among 
traditional societies (Malinowski, 1922; Cordwell and Schwarz, 1979; Carey, 1986; Sanders, 2002; McAdam, 2008; Casella, 2012; McAdam and Davidson, 2018; Balme and O'Connor, 2019), the reconstruction of past population dynamics requires detailed investigation of the practices associated with personal ornament manufacture and pigment use. Such informative potential is even higher in East Asia considering the relatively undiagnostic character of early Late Paleolithic lithic industries, most often attributed to either core-and-flake or blade technologies.

Prior to the current study, it was believed that owing to the regrettable loss of the Zhoukoudian collections during the Second World War, the information available on the personal ornaments and mineral pigments found by Pei Wen Chung during his excavation at UC was restricted to the illustrations and descriptions contained in his monograph (Pei, 1939), a few plaster casts of ornaments curated at the Institute of Vertebrate Paleontology and Paleoanthropology (IVPP) in Beijing, and two perforated teeth reported by Sina News on their website in 2005 (Sina News, 2005), exhibited at the Zhoukoudian Site Museum (ZSM). In his monograph, Pei provided information on the stratigraphic provenience of personal ornaments and ochre fragments and proposed a taxonomic attribution for the perforated teeth, shells and fish bone. He further attempted to identify perforation techniques, use-wear, and notices the presence of ochre residues on some ornaments. By examining the excellent iconography contained in Pei's monograph (1939) and the available casts, we realized more information could be gleaned from a reappraisal of these sources using modern analytical approaches.

With this in mind, this study addresses the following aims: 
Our first aim is to present the results of a detailed analysis of Pei's photographs and drawings, which provide novel information on raw material selection, the techniques used by UC visitors to produce personal ornaments and their evolution through time.

Inspection of the new ZSM premises allowed us to discover that not all personal ornaments had been lost during the Second World War. Thus, our second aim is to submit the rediscovered specimens to an in-depth technological and use-wear analysis.

Numerous pieces of ochre with anthropogenic modifications and red pigment residues attached to objects and human remains were reported by Pei (1939). However, the loss of the Zhoukoudian collections prevented their chemical characterization. Thus, our third aim is to analyze ochre residues adhering to the personal ornaments rediscovered at the ZSM to gather information on the composition of pigments used by UC people.

Our fourth aim is to combine technological, use-wear and residue analysis to establish how ZSM ornaments were worn and propose hypotheses on their role in social interactions and group recognition.

Our fifth aim is to study the two purported ornaments exhibited at the ZSM. We show they are fossilized teeth perforated recently to transform them into personal ornaments.

Lastly, we investigate variation in Northern Chinese Paleolithic personal ornaments to identify cultural dynamics, defined as the processes and mechanisms responsible for the maintenance, decline or expansion of cohesive cultural entities (d'Errico and Banks 2013)

Collectively, our results provide novel perspectives on the complexity and evolution of symbolic practices enacted by Homo sapiens populations living in East Asia during the Late Pleistocene. We document two long-lasting cultural traditions possibly mirroring population 
structure, and demonstrate the value of reassessing old iconography and collections with new methodologies in light of emerging questions.

\subsection{Archaeological context}

UC, also known as Zhoukoudian Locality 26 (Shen et al., 2016), is one of the 27 archeological and paleontological sites located in the Zhoukoudian region, $48 \mathrm{~km}$ southwest of Beijing ( $\left(39^{\circ} 41^{\prime} 21^{\prime \prime} \mathrm{N}, 115^{\circ} 55^{\prime} 26^{\prime \prime} \mathrm{E}\right)$. The cave is located directly above the southwest wall of Zhoukoudian Locality 1, the famous 'Peking Man' site, where Pei and his team unearthed numerous Homo erectus remains (Shen et al., 2016). Discovered in 1930 and excavated in 1933 and 1934 by Pei and his team, the UC infilling consisted of grey sediments and slightly consolidated, fossiliferous breccia with limestone blocks collapsed from the cave wall and ceiling (Pei, 1939). Within the $>10$ meters sedimentary sequence, Pei identified five cultural layers, L1 (top) to L5 (bottom), overlying a 'Lower Recess' filled with archaeologically sterile sediment (Pei, 1939; Norton and Gao, 2008). The schematic sections drawn by Pei (Fig. 1) show that what he calls 'cultural layers' are in fact thin archaeological horizons separated from one another by $2-3$ meters of undifferentiated deposits, in some cases containing isolated archaeological items. At the bottom of the sequence, a thick, discontinuous, stalagmitic layer separates the UC Late Pleistocene infilling from the red-colored, hard sediments identified as layers 1-2 in the Zhoukoudian Locality 1 sequence and now dated to $400 \mathrm{ka}$ (Shen et al., 2001, 2009). According to Pei (1939:38), burrowing animals, such as the badger, caused horizontal and vertical displacements of archaeological material. Li and colleagues suggest this is particularly the case close to the edges of the deposit where ${ }^{14} \mathrm{C}$ ages appear inconsistent (Li et al., 2018). 
UC yielded a rich faunal assemblage, which encompasses more than 50 species of fishes, reptilians, amphibians, mollusks, birds, and mammals (Pei, 1940). Mammals dominate the faunal spectrum with cervids being the most represented herbivore, rabbits accounting for most of the rodents, and foxes (Vulpes vulgaris, $V$. corsac) and badgers (Meles sp.) constituting the bulk of the carnivore guild. All taxa are disproportionately represented by cranial elements. The presence of at least 30 articulated cervid skeletons in the Lower Recess combined with the absence of human and cultural remains in this locus together support its interpretation as a natural trap (Pei, 1939; Norton and Gao, 2008). Anthropogenic modifications documented on faunal remains from L1 to L5 include cut marks and exposure to heat. Carnivore tooth marks were also recorded, indicating that carnivores may have played a role in the accumulation of bone (Norton and Gao, 2008).

Numerous $H$. sapiens remains attributed to at least eight individuals were found at UC. Pei (1939) mentions the presence of isolated human bones in L1 and L2, and isolated teeth in L4 and L5. In the sediments sandwiched between L3 and L4, below a limestone overhang, Pei discovered three complete human skulls (UC101, UC102, UC103), and numerous other human remains. The presence of ochre coating on all skulls, personal ornaments on UC102, and the discovery of several articulated postcranial elements, encouraged Pei (1939) and Weidenreich (1939) to interpret these remains as burials of individuals interred together, or over a relatively short timespan, that were later disturbed by carnivores. Recent morphometric analyses of the casts of these skulls have led authors to refute the hypothesis that the three individuals belonged to the same family, and suggest instead that their morphometric variability reflects variation within a broader penecontemporaneous Asian Pleistocene population (Cunningham and Wescott, 2002), ancestral to Paleoamericans (Cunningham and Jantz, 2003). 
The UC lithic assemblage comprises only 25 pieces and fits the definition of the Northern Chinese core-and-flake technology. Quartz is the main raw material $(n=17)$ followed by flint $(n$ $=4)$, sandstone $(n=3)$, and chert $(n=1)$. Hard hammer and bipolar techniques are the preferred knapping strategies for the production of flakes that were later retouched into scrapers and endscrapers. Bone tools are rare. The only formal bone tool consists of an eyed needle found in L1 (Pei, 1934, 1939; d'Errico et al., 2018). A few mammalian long bone fragments bearing unusual flake scars were interpreted by Pei as knapped bone tools (Pei, 1939). Pei describes two other anthropogenically modified osseous objects: a lower mandible of a large Sika deer (Cervus nippon) with an unusual polish, and the basal portion of a Wapiti antler (Cervus elaphus canadensis) polished and decorated with a criss-cross pattern of thin engraved lines (see Fig. 10, Plate VI in Pei, 1939; see also Supplementary Online Material [SOM] Figs. S1 and S5).

Contrary to stone or bone tools, cultural remains usually interpreted as evidence for symbolic behavior were found in large number at UC (Table 1). Pieces of red ochre, described by Pei as 'oolitic hæmatite', were frequently unearthed throughout the sequence. One of them measured 20 $\mathrm{cm}$ in length and some specimens bore clear traces of grinding to produce ochre powder and a smoothed area suggesting the use of these pieces in a fashion similar to crayons. Ochre particles were abundantly found in the sandy clayish matrix adhering to the human skulls. An oval limestone fragment exhibited three faint, oval, red patches. Ornaments were exclusively found in L2 and L4, with the exception of seven limestone beads attached to skull UC102 and a deer canine recovered in close proximity. Ornaments from L2 consist of fox and badger perforated canines and a single notched bone tube. L4 yielded the bulk of the ornaments and the most diverse sample, including perforated carnivore and herbivore teeth, marine shells attributed to Arca sp., and a perforated pebble made of a volcanic rock. Three notched bone tubes, found in 
the sieving, may also have come from this layer. The stratigraphic provenience of a perforated fish supraorbital bone attributed to Ctenopharyngodon idlla is unknown, although Ciprinidae remains were found exclusively in L4.

Attempts to date the UC sequence by TL, U-series, conventional and AMS ${ }^{14} \mathrm{C}$ were carried out between 1977 and 1992. They yielded ages ranging between 50 and $10 \mathrm{ka}$, with numerous stratigraphic inconsistencies (ZK The Institute of Archaeology, Chinese Academy of Social Sciences, 1977, 1980; Chen et al., 1984, 1989, 1992; Pei, 1985; Chen and Zhang, 1991; for a review, see Li et al., 2018). The most recent study, based on the AMS ${ }^{14} \mathrm{C}$ dating of 11 faunal remains, proposes that the deposition of L4 occurred between $38.3-35.8 \mathrm{ka}$, and that of L1 between 35.1-33.5 ka (Li et al., 2018). This proposed chronology, however, should be taken with caution considering that 1) 12 AMS ${ }^{14} \mathrm{C}$ ages produced by previous studies situate the accumulation of the UC sequence between 44.5 and $15.3 \mathrm{ka}$; 2) the ages obtained by Li et al. (2018) range between 50 and $33.5 \mathrm{ka}$; and 3) the remains dated by Li et al. (2018) were attributed to Pei's cultural layers on the basis of their excavation date compared to that of the discovery of key finds with known stratigraphic origin. In some cases, the dated remains were found the day before or after the stratigraphically attributed key finds; in others, between three and 15 days had lapsed between the discovery of the key finds and the dated remains. Li et al. (2018) attributed the marked difference between their and previous results to the application of collagen ultrafiltration pretreatment. It is unclear, however, how the lack of such pretreatment would have produced in previous studies numerous AMS ages between 23 and 27 ka, i.e., 5-10 kyr younger than those obtained during the last dating campaign. In sum, although the most recent study has not entirely resolved the chronology of the UC sequence, it is reasonable to think that the personal ornaments found at UC, discovered in cultural layers L2, L4 and in association with the 
UC102 skull, found between L3 and L4, are older than $33.5 \mathrm{ka}$, the minimal age for L1. If Li et al.'s (2018) dates for L1 are taken as a terminus ante quem, the UC ornaments are likely older than $35 \mathrm{ka}$ and possibly as old as $38.3 \mathrm{ka}$.

\section{Materials and methods}

In the present study, we exploit seven different sources of information: 1) contextual data on the stratigraphic provenience of personal ornaments and their association with possible burials; 2) technological descriptions, photographs, drawings and color plates included in Pei's (1939) monograph (SOM Figs. S1-S7; SOM Table S1); 3) good quality casts of 17 objects produced in 1939 and curated at the IVPP; 4) the direct analysis of two unpublished objects displayed at the ZSM, the photographs of which were available on the internet (Sina News, 2005) when we started the project but had not yet been studied; 5) the analysis of three perforated teeth rediscovered during a visit at the new ZSM in May 2014 by four of us (F.d'E., A.P.M., M.V., and X.G.); 6) the chemical characterization of red residues and sediment still adhering to these three ornaments; and 7) a database of personal ornament types found at Northern Chinese sites based on data mined from the literature (An, 1965; Jia et al., 1972; Gai and Wei, 1977; Huang et al., 1986; Xie et al., 2006; Mei, 2007; Song and Shi, 2013; Wei et al., 2016, 2017; Pitarch Martí et al., 2017; Li et al., 2020), which integrates changes in the taxonomic attribution of UC personal ornaments on teeth proposed in the present study.

\subsection{Taxonomic and skeletal element identification}


In his monograph, Pei (1939) proposed a taxonomic identification for 129 of the 133 ornaments made of teeth, bone and shell. Four bone tubes lacked diagnostic features to propose an identification. To verify Pei's taxonomic identification and, whenever possible, obtain information on the anatomical position of the element and age of the animals, we compared the iconography presented in his monograph with mammal teeth kept in the zoological reference collection curated at the PACEA laboratory, Bordeaux. To distinguish upper from lower fox canines as well as to side those teeth, we used criteria synthesized by Vercoutère (2003). Sex and age determination of red deer canines followed the protocol established by d'Errico and Vanhaeren (2002). Sex determination was based on the tooth's morphology and the root width/thickness ratio. Young stag canines have a globular shape that tends, due to use-wear, to become triangular in older animals. Crowns of young hinds are pointed and become rectangular in old animals. The root width is always more than twice its thickness among stags and less so among hinds (d'Errico and Vanhaeren, 2002). Age estimation relied on two complementary methods. The first method, based on qualitative variables, included 1) five stages of occlusal wear, 2) three stages of root development, 3) the state of calcification of the pulp cavity, and 4) the removal by wear of the disto-linguo-cervical lobe. The second method involved the use of two regression equations, one for stags and the other for hinds. For stags, the equation considered the lengths and widths of the crown, root and wear facet. For hind, the equation took into account the crown length, width and thickness, and the wear facet length and width. Marine bivalves were attributed by Pei to Arca sp. In the absence of information on color, we reassessed the taxonomic identification of these shells by relying on the distribution of Arcidae species and morphological and ornamental criteria, i.e., shell form, umbo (the pointed prominence of a bivalve shell) position relative to the anterior/posterior axis, concentric growth lines, orientation 
and morphology of radial ribs, and crenulation of the ventral margin, (Bernard et al., 1993; Qi, 2004; WoRMS Editorial Board, 2021).

\subsection{Technological and morphometric analysis}

Iconography of personal ornaments provided by Pei (1939) was scanned with an Epson Perfection V660 photoscanner at a resolution of 2400 dpi (SOM Figs. S1-S7) and analyzed to recover information on perforation size (small, medium, large), its location on the root with the crown oriented downward (top, medium, low), orientation/shape relative to the tooth main axis (circular, vertical, horizontal, oblique), and technology (unidirectional incising, bidirectional incising, radial incising, piercing by rotation, grinding). Incising to carve a perforation is produced by the repeated displacement — unidirectional, bidirectional or radial—of a pointed lithic tool. A correspondence analysis was performed with these categorical variables using PAST v. 2.1 (Natural History Museum, Oslo; Hammer et al., 2001). The casts and rediscovered original ornaments were scanned at a resolution of 2400 dpi with an Epson Perfection V660 Photoscanner and photographed with a Canon PowerShot S100 camera. Microscopic analysis of the rediscovered specimens was conducted using a Leica Wild M3C stereomicroscope equipped with a Nikon CoolPix E990 digital camera at magnifications of 4-40×. Identification of manufacturing techniques and use-wear traces was based on observations of ethnographic, experimental and archaeological ornaments (Vanhaeren and d'Errico, 2001, 2002, 2005, 2017;

d'Errico and Vanhaeren, 2002; White, 2007; d'Errico and Rigaud, 2011; Rigaud, 2013; Vanhaeren et al., 2013; Rigaud et al., 2014, 2017; Wei et al., 2016, 2017; Cvitkušić, 2017;

d'Errico et al., 1993, 1998, 2017; Pitarch Martí et al., 2017; Cârciumaru et al., 2019; Arrighi et 
al., 2020; Niekus and Amkreutz, 2021). Morphometric data were collected with a digital caliper and rounded to the nearest $0.01 \mathrm{~mm}$; variables include maximum length, width and thickness for each specimen as well as the minimum and maximum diameter of the perforation.

\subsection{Residue analysis}

Bright red residues located around the perforations of the three rediscovered teeth (Fig. 2) and a greyish coarser sediment still adhering to the root of the complete specimen (Fig. 2A) were sampled under a reflected light microscope with single-use, sterilized scalpels. The four samples were photographed with a motorized Leica Z6 APOA equipped with a DFC420 digital camera linked to a LAS Montage and Leica Map DCM 3D computer software (Leica, Heerbrugg) at the PACEA laboratory, Bordeaux. The samples were analyzed with a FEI Quanta 200 scanning electron microscope under a low vacuum mode by using an accelerating voltage of $15 \mathrm{kV}$. Backscattered electron images were collected with a SiLi detector. EDS spectra were obtained with a SDD-EDAX detector. Four magnifications were set for the EDS analyses of each sample, i.e., $500 \times, 1000 \times, 1750 \times$, and $3500 \times$. The working distance was kept constant at $10 \mathrm{~mm}$. Acquisition time was set up to 100 seconds for each EDS spectrum. Raman analysis was conducted with a SENTERRA Dispersive Raman Microscope. The analyses were done with a $785 \mathrm{~nm}$ laser and a laser power of $1 \mathrm{~mW}$ to avoid thermal photodecomposition on the analyzed area. Acquisition time was set to 20 seconds and multiple co-additions. The spectrometer worked in a spectral range from 65 to $2980 \mathrm{~cm}^{-1}$. The working areas were observed through an integrated color camera INFINITY1. Data were collected and processed with OPUS v. 7.2 (Bruker Optik GmbH, Ettlingen). The mineral phase identification was based on comparisons of the recorded 
spectra with those of several spectra libraries (de Faria et al., 1997; Castro et al., 2005; Lafuente et al., 2016).

\subsection{Seriation}

Data on reported occurrences of Late Pleistocene personal ornaments in Northern China were compiled from the available literature (An, 1965; Jia et al., 1972; Gai and Wei, 1977; Huang et al., 1986; Xie et al., 2006; Mei, 2007; Zhang et al., 2010; Song and Shi, 2013; Wei et al., 2016, 2017; Song et al., 2017; Pitarch Martí et al., 2017; Li et al., 2019; Li et al., 2020). During our 2014 visit to the IVPP, we reassessed the taxonomic identification of the perforated teeth found at Xiaogushan and attribute both carnivore canines to $V$. vulpes based on their more pronounced curvature and crown morphology (Pales and Garcia, 1981a; Berkovitz and Shellies, 2018).

Seriation of a presence-absence matrix of ornament types (columns) and archaeological layers (rows) was performed in PAST v. 2.1 (Natural History Museum, Olso; Hammer et al., 2001). The seriation routine reorganized the data matrix such that the occurrences are concentrated as much as possible along the diagonal. We used the unconstrained mode, where both rows and columns are free to move. Occurrences were given different colors according to their chronology.

\section{Results}

\subsection{Taxonomic reassessment}


Pei (1939) reports the discovery of 125 perforated teeth belonging to nine mammalian species. In decreasing order of identified specimens, the species are badger (Meles meles and $M$. leucurus), common fox ( $V$. vulpes), red deer (Cervus elaphus/canadiensis), corsac fox ( $V$. corsac), Sika deer (C. nippon), weasel (Mustela sp.), roe deer (Capreolus capreolus), and tiger (Panthera tigris). However, Pei only provided photographs and/or drawings for 83 teeth (SOM Table S1). Bearing in mind the difficulty of proposing a taxonomic attribution on the basis of images rather than the actual objects, our reassessment (SOM Table S1) endorses to a large extent Pei's original identifications, with the possible exception of two specimens: a lower canine originally interpreted as belonging to a Mustela sp. which we attribute to a Martes sp. because of its larger size and more pronounced curvature, and a tiny pointed tooth originally identified as a C. capreolous deciduous lower canine, which we identify with a high degree of certainty as a red deer deciduous upper canine, since roe deer do not have canines (Pales and Garcia, 1981b) and the size and morphology of the specimen is fully consistent with our identification (d'Errico and Vanhaeren, 2002). Reappraisal of the three marine bivalves attributed by Pei to Arca sp. suggests, based on the present distribution of Arcidae species in the Yellow Sea, on shell form, umbo position relative to the anterior/posterior axis, concentric growth lines, orientation and morphology of radial ribs, and crenulation of the ventral margin, that one specimen (Fig. 3A) should be attributed to Anadara disparilis (Reeve, 1844) or $A$. satowi (Dunker, 1882) and the two others (Fig. 3B, C) to A. broughtonii (von Shrenck, 1867). The only personal ornament made of fish bone was identified at Pei's request by Tchang Tchun Lin (1897-1963), at the time a well-known ichthyologist specializing in the study of Cyprinidae, as a supraorbital bone of a Ctenopharyngodon idellus, or grass carp, now called C. idella (Cuvier and Valenciennes 1844). The size of the bone indicates a fish length of ca. $65 \mathrm{~cm}$. The bone 
tubes interpreted by Pei as ornaments do not retain morphological features allowing their taxonomic identification. Their thickness and absence of spongy bone suggested to Pei they were probably of avian origin, an attribution that is difficult for us to assess from casts and drawings.

\subsection{Teeth, sex and age identification}

Thirty-nine of the 60 badger teeth found by Pei-we have a single surviving cast (Fig. 3K; Table 2)—are illustrated in his 1939 monograph (SOM Figs. S2, S4, S6 and S7; SOM Table S1). We identified 26 lower canines including nine right and four left, as well as 13 upper canines among which are two right; 13 lower canines and 11 upper canines could not be attributed to either side (SOM Table S1). By comparison to modern specimens, variation in size and use-wear suggest juvenile and both younger and older adults are represented. The three teeth rediscovered at the ZSM correspond to two lower left and one lower right badger canines (Fig. 2; Table 2). We were not able to identify these specimens in the pictures and drawings provided by Pei (1939). They probably belong to the group of 21 teeth not illustrated in the monograph. Twenty-

five of the 37 fox teeth found by Pei-we have casts for three of them (Fig. 3L-N; Table 2) -are illustrated in his 1939 monograph (SOM Figs. S6 and S7; SOM Table S1). We identified, in decreasing order, 10 upper right, four upper left, four lower right and three lower left canines as well as four upper canines that we were not able to side (SOM Table S1). Variation in size and use-wear suggest a wide range of ages is represented, from very young to very old.

The thirteen permanent red deer canines belong to three stags and nine hinds (SOM Figs. S1 and S6; SOM Table S1). We have three surviving casts (Fig. 3O-Q; Table 3 Nos. 1-3). This minimum estimate of the number of individuals (MNI) accounts for the fact that two 
morphologically similar hind canines almost certainly come from the same individual (SOM Figs. S1 Panel 4C, D and S6 Items 3a-4b); SOM Fig. 1). Analysis of Pei's photographs and drawings indicate mature and old individuals are disproportionately represented (SOM Table S1). A more precise age attribution was obtained from data collected on the three surviving casts (Table 3 Nos. 1-3). One stag canine and one hind canine were given an age of 7.83 and 9.50 years, respectively (Fig. 3P, Q; Table 3 Nos. 2 and 3; SOM Table S1). These age estimations are based on the application of regression equations derived from modern teeth of known age, which take into account lengths and widths of the crown, root and wear facet for stags, and the crown length, width and thickness as well as the wear facet length and width for hinds (d'Errico and Vanhaeren, 2002). The age of the other canine, with an incipient facet that could not be measured on the cast, was attributed based on qualitative characters (d'Errico and Vanhaeren, 2002). It features an incipient occlusal wear, an open root apex, a visible pulp cavity and a preserved disto-linguo-cervical lobe. This association of characters indicates the tooth comes from a 2-4-year-old stag (Fig. 3O; Table 3 No. 1). The deciduous red deer canine (SOM Figs. S2 and S6; SOM Table S1) belongs to a one-year-old stag or hind, the time at which red deer loses these teeth. The tiger lower lateral incisor features a heavily worn crown indicative of an old individual (SOM Figs. S2 and S6; SOM Table S1). Data on grass carp development suggests that, based on its length $(24.56 \mathrm{~mm})$, the perforated supraorbital bone belongs to an eight-yearold individual (Milardi et al. 2015).

\subsection{Technology}


Analysis of Pei illustrations shows that less than half of the depicted teeth (46\%) were perforated with the application of a single technique: a third of these (31\%) were perforated by incising their root with a pointed tool moving from the root apex toward the crown (unidirectional incising), 27\% were perforated by incising their root with the to-and-fro movement of a lithic point (bidirectional incising), 23\% by incising the roots radially, and $19 \%$ by rotation (SOM Table S1). The remainder of the teeth $(54 \%)$ were perforated by associating two techniques. In $59 \%$ of these cases, the root was first ground to produce a concave facet and then perforated by radial incising (18\%), unidirectional incising (15\%), rotation (15\%), and bidirectional incising (11\%). In $41 \%$ of these cases, the root was first incised with a unidirectional (37\%) or bidirectional (4\%) movement and then perforated by rotation (SOM Table S1). No perforation technique is systematically associated with a tooth type or species. In contrast, a striking correspondence is observed between the two main cultural layers (L2 and L4) and the perforation techniques (Fig. 4). Radial incising is typically found in L2, bidirectional incising in L4. The three other techniques, i.e., grinding, unidirectional incising and rotation, are found in both layers.

Pei hypothesized that the Anadara valves were perforated by rubbing the umbo- the pointed prominence of a bivalve shell —against a sandstone. Analysis of the photos and casts applying experimental criteria (d'Errico et al., 1993; Wei et al., 2016) contradicts this hypothesis. No striated facets typical of the technique proposed by Pei are visible around the perforations, which display irregular edges consistent with a perforation produced by percussing the umbo and roughly regularizing the resulting perforation by rotation. This interpretation is further supported by the morphology of the fracture on the A. disparilis/satowi (Fig. 3A; SOM Fig. S3), suggestive of a percussion inflicted tangentially on the apex of the umbo, which resulted in the removal of a 
large triangular flake. Bifacial perforation by rotation was applied with a sharp point on the fish bone (Fig. 3J; SOM Fig. S3). The pebble was first flattened by abrading one aspect with a movement oblique to the object's main axis and then perforated by rotating a robust lithic tool on both sides (Fig. 3D; SOM Figs. S3 and S4). The thickness and probable hardness of the pebble indicate the perforation must have been a time-consuming task. Of the five illustrated stone beads found on skull UC102, between L3 and L4, three bear clear traces of a unifacial perforation by rotation followed by a rough regularization of the hole on the opposite side, producing microchipping (Fig. 3E, F; SOM Figs. S1, S3 and S4). This technique was applied before the final shaping of the blank by unifacial trimming, as observed in some manufacturing sequences of archaeological and ethnographic ostrich egg shell beads (OESB; Kandel and Conard, 2005; Vanhaeren, 2005; Orton, 2008; Wei et al., 2017; d'Errico et al., 2020; Backwell and d'Errico, 2021). The application of trimming is demonstrated by the diagnostic denticulated edge visible on one bead (Fig. 3E; SOM Fig. S3). On two other specimens, the serrated edge appears smoothed, which may have been caused by intentional regularization by grinding or usewear. Another stone bead has a rounded shape and displays no traces of trimming, indicating that regularization by grinding was applied to at least some beads. Interestingly, the size and sections of the perforations on the stone beads with traces of trimming are very similar to those on the pebble from L4, possibly reflecting a lasting know-how.

Judging from their photos, drawings and available casts (Fig. 3G-I; SOM Figs. S2 and S3), the four bone tubes lack diagnostic features to identify how they were made and whether all modifications are anthropogenic in origin. Traces left by stone tools are generally detectable on transverse notches and grooves decorating bone rods (Laroulandie and d'Errico, 2004; Wright et al., 2014; Shunkov et al., 2020). In contrast, grooves on UC tubes are U-shaped in section and 
appear exceedingly shallow and polished. They may have been produced with an uncommon technique, difficult to identify on available evidence, or be of natural origin. Although the section of the tube ends is compatible with a sawing made by a robust cutting edge, no traces of the application of this technique are detectable. Disappearance of manufacturing traces may have been produced by intense wear.

\subsection{Rediscovered tooth pendants}

The three rediscovered teeth consist of two lower left (Fig. 2A, C) and one lower right (Fig. 2B) canines of badger. Only one specimen is complete (Fig. 2A); the two others are broken at the level of the perforation. The factures display both ancient and recent breakages indicating the ornaments were either lost or discarded at the site in Paleolithic times and their original fractures subsequently damaged during recovery or curation. The three objects are entirely coated with a transparent varnish, which has preserved their surface and adhering residues. Two types of residues are recognized: 1) a grayish coarse sediment covering the labial aspect of the root apex on the complete tooth and the area between the perforation and neck on the same aspect (Fig. $2 \mathrm{~A})$, and 2) bright red residues concentrated around and inside the perforations on all ornaments and present in the form of micro-spots and stains all over their surfaces (see section 3.5 for more details). When co-occurring, microscopic analysis reveals the grayish residues systematically cover the red residues. This observation indicates the red residues are remnants of the ochre compounds covering the objects while they were used as ornaments in the Paleolithic, and the grayish residues consist of archaeological sediments coating them at the time they were found. 
Microscopic analysis identifies commonalities and differences in the way the three teeth were modified. All teeth display on the labial aspect a large, flat facet extending over a large portion of the root (Figs. 2 and 5B, D, I). The incomplete specimens only preserve half of this facet. The facets were made before perforating the teeth. Although no traces of the technique used to produce these facets is observed due to subsequent wear, their morphology suggests they were originally produced by grinding (for comparable examples of the effect of grinding on the morphology of osseous objects, see David, 2004; d'Errico and Rigaud, 2011; Vanhaeren et al., 2013; Langley et al., 2016; Wei et al., 2016; d'Errico et al., 2018; Zhang et al., 2018). The main differences identified among the three teeth relate to their perforation. Two techniques were used on the incomplete specimens to achieve the perforations on the facets, i.e., on the labial aspect of the teeth. In one case the broken perforation bears traces of rotation (Figs. 2B and 5D), in the other the rotation was preceded by whittling (Figs. $2 \mathrm{C}$ and $5 \mathrm{I}$ ). On the complete tooth, the perforation on the facet was probably hollowed by whittling and later enlarged and regularized by rotation with a stone tool (Figs. 2A and 5B). Three techniques were used to perforate the lingual aspect of the teeth roots. On the complete specimen, the section of the perforation widens toward the crown, suggesting the hole was made by incising unidirectionally or radially the root with a lithic point in the direction of the crown (Figs. 2A and 5A). On one of the broken specimens (Figs. 2B and 5E), the hole was carved with the same motion albeit using a more pointed tool, which has left a distinct large groove filled with ochre. On the other broken specimen, the lingual aspect of the root was gouged with the edge of a robust lithic tool, which produced a concave surface displaying thin longitudinal parallel striations crossed by chatter marks (Figs. $2 \mathrm{C}$ and $5 \mathrm{H}$ ). The perforation was achieved by rotation. 
On the complete tooth, use-wear takes the form of shallow notches located, on the lingual aspect, on either side of the perforation (Fig. 5A). On the labial aspect of this tooth, ochre-filled subparallel micro-striations are found on the left of the perforation (Fig. 5B, C). Grey sediment covering the ground facet prevents detection of eventual use-wear traces on this area. On the labial facets of the broken teeth, sub-horizontal, ochre-filled, parallel and slightly curved microstriations are present below the perforation (Fig. 5G, J). On the lingual aspect of a broken tooth, ochre-filled randomly oriented micro-striations are seen on the left of the perforation (Fig. 5F).

\subsection{Residue analysis}

Greyish residue on the complete tooth 1 Under optical microscopy, the residue appears as an admixture of up to $100 \mu \mathrm{m}$ in length with angular and sub-angular grains featuring different shades (colorless, white, yellow and, less often, orange and black; Fig. 6 A, B). SEM-EDS shows that the residue is composed of sub-rounded silicate crystals (ca. $40 \mu \mathrm{m}$ in length; $\mathrm{Si}$ ), equiaxed platelets and sub-angular aluminosilicate crystals (ca. 5-20 $\mu \mathrm{m}$ in length; $\mathrm{Si}, \mathrm{Al}, \mathrm{Mg}, \mathrm{Ti}, \mathrm{Fe}$ and traces of $\mathrm{Ca}, \mathrm{K}, \mathrm{P}, \mathrm{Na})$, as well as sub-angular iron/titanium-rich oxy-hydroxide crystals $(<2 \mu \mathrm{m}$; $\mathrm{Fe}$ and Ti) unevenly distributed within the matrix. Traces of $\mathrm{P}$ and $\mathrm{S}$ were also detected (Fig. 6C-E; Table 4). Micro-RS analyses did not produce diagnostic spectra, probably due to the presence of clays, which generates strong fluorescence when excited by laser beams (Košařová et al., 2013).

Red residue on complete tooth 1 Observed under the optical microscope (Fig. 7A, B), the residue appears as a heterogeneous material composed of silt to sand sized (ca. 20-250 $\mu \mathrm{m}$ ), sub- 
angular, translucent white and black particles agglomerated by tiny red crystals. SEM-EDS analysis shows sub-angular crystals identified as iron/manganese-rich oxy-hydroxides (up to $8 \mu \mathrm{m}$ in length; $\mathrm{Fe}, \mathrm{Mn}$ ) and feldspars (ca. $140 \mu \mathrm{m} ; \mathrm{Si}, \mathrm{Al}, \mathrm{Na}, \mathrm{K}, \mathrm{Ca}$ ) as well as platy-like particles $(10-50 \mu \mathrm{m})$ probably aluminosilicates, and small angular crystals $(<6 \mu \mathrm{m}$ in length; Fe, Mn) mixed with tiny platelets ( $<2 \mu \mathrm{m}$; Si, Al, K, Ca, Na, Mg, Ti; Fig. 7C-F; Table 4). Micro-RS analysis confirmed the presence of hæmatite and feldspars (microcline) and detected the presence of calcite and possibly sulphates (Fig. 8A; Table 5). As with the greyish residue from the same tooth, the intense spectral background may indicate the presence of clays.

Red residue from broken tooth 2 Apart from its finer granulometry, this residue, composed of up to $20 \mu \mathrm{m}$ sub-angular translucent and black grains embedded in a reddish matrix, appears similar to that adhering to complete tooth 1 (Fig. 9A, B). Likewise, its elemental composition is characterized by a substantial amount of micrometric sub-angular crystals (ca. $2-4 \mu \mathrm{m}$ in length) of iron oxy-hydroxides with variable proportions of manganese in association with platelets of clay minerals ( $<2 \mu \mathrm{m}$; $\mathrm{Si}, \mathrm{Al}, \mathrm{Ti}, \mathrm{K}, \mathrm{Mg}, \mathrm{Na}$ ), micrometric lath-like $\mathrm{Na}$ and $\mathrm{K}$-rich feldspars (ca. 3.5-10 $\mu \mathrm{m}$ in width and $10-25 \mu \mathrm{m}$ in length), sub-angular carbonate crystals (ca. $2-4 \mu \mathrm{m}$; Ca) and rounded silicate crystals (ca. $15 \mu \mathrm{m}$ length; $\mathrm{Si}$ ). Traces of $\mathrm{P}, \mathrm{S}$ and $\mathrm{Cl}$ are sporadically detected (Fig. 9C-F; Table 4). Micro-RS analyses identify hæmatite, quartz and muscovite (Fig. 8B; Table 5).

$\underline{\text { Red residue from broken tooth } 3}$ This residue features a granulometry and crystal morphology similar to that found on broken tooth 2, i.e., a material composed of micrometric sub-angular, translucent and black crystals in a matrix of red particles (Fig. 10A, B). However, its color is 
darker. SEM-EDS analyses shows that the sample is composed of sub-angular crystals (30 $\mu \mathrm{m}$; $\mathrm{Si}, \mathrm{Al}, \mathrm{K}, \mathrm{Ca}, \mathrm{Mg}, \mathrm{Na}$ ) coated with a mix of platy-like and sub-angular crystals ( $<5 \mu \mathrm{m}$ in length; Fe, Mn together with Si, Al, Ca, K, Mg, Na; Fig. 10C-E; Table 4). As with the previous two red residues, $\mu$-RS analyses identified hæmatite and quartz (Fig. 8C; Table 5), and an intense spectral background suggesting the presence of aluminosilicates.

\subsection{Identification of fake personal ornaments}

The two objects displayed at the ZKM consist of a canine fragment from an unidentified large felid (Fig. 11A; Table 2 No. 18) and the right canine of an adult male red deer (Fig. 11B; Table 3 No. 4). Quantitative and qualitative methods for age estimation (d'Errico and Vanhaeren, 2002) indicate the red deer canine comes from a 14-year-old stag (Table 3 No. 4). The tooth is substantially smaller than the stag canines illustrated in Pei's (1939) monograph and those preserved as casts. Both the felid canine and the red deer canine display a partial exfoliation of the cementum and manganese dendrites indicating an advanced stage of fossilization. Microscopic analysis shows that the perforations on these teeth markedly differ in technology, shape, size, use-wear and occurrence of residues from the rediscovered badger canines, available casts, and the teeth depicted in Pei's monograph (Figs. 2 and 3; SOM Figs. S2, S4, S6 and S7). To perforate these teeth, a flared, probably lithic, point was first used in a rotating motion to create incomplete conical perforations on both aspects of the tooth. The use of a lithic point in this stage of the perforation is supported by the morphology of the striations indicating the motion of an irregular serrated edge. A thinner, conical, possibly metal, drill, was then applied to both aspects to complete the perforations (Fig. 12). The characteristic opposing double funnel- 
like section produced by this technique is not seen on any tooth documented from UC thus far. The perforation diameter is tiny when compared to those recorded on the rediscovered teeth, on the casts and on the ornaments depicted by Pei. The only exception with a perforation comparable in size is the deciduous red deer canine, where the perforation diameter is constrained by the very small width of its root (SOM Fig. S6). Striking similarities in section and perforation diameter suggest the same tools, if not the same person, produced the perforations on both teeth (d'Errico and Vanhaeren, 2002; Henshilwood and d'Errico, 2005). The crenulated outline of the edges and the microflake scars around them indicate the perforations were made on already fossilized teeth. The striations left on the holes by the rotating tools are very fresh and do not show the darker patina present on the unmodified surface of the teeth. No use-wear is detected on the hole surfaces nor on the remainder of the teeth, unlike the rediscovered badger canines and the teeth depicted by Pei (1939). No residues of pigment or sediment, found by Pei on a number of teeth and abundantly present on the rediscovered ornaments, are found inside the holes.

\subsection{Northern Chinese personal ornaments seriation}

Two interesting features appear when examining the seriation of Northern Chinese Paleolithic personal ornaments (Fig. 13). First, the seriation identifies two groups of sites characterized by different personal ornament types. The first group, comprising the Shuidonggou, Shizitan and Hutouliang site complexes, and Lingjing, layer 5, is dominated by OESBs, ostrich egg shell (OES) pendants, and perforated bivalves. The second group, including UC, Xiaogushan and Shiyu, presents ornaments consisting of perforated mammal teeth and to a 
lesser extent stone beads, perforated pebbles and perforated marine bivalves. Bone tube is the only ornament shared by the two groups. Finally, stone and bone pendants were only found at the Hutouliang site complex and Xiaogushan layer 3. Second, while the sites of the first group cover the entire timespan examined, i.e., from 40 to $10 \mathrm{ka}$, those from the second group only belong to the first time slice, i.e., 40-30 ka, with a single site, Xiaogushan, layer 3, dated to the second, i.e., $30-25$ ka.

\section{Discussion}

The reappraisal of UC personal ornaments, including rediscovered specimens, and comparison with available data on the earliest traditions of body decoration in Northern China, provide new insights into early ornamentation practices of this region. The striking differences observed between the two teeth displayed at the ZSM and those described by Pei (1939) and by ourselves in the current study, strongly suggest that the former are fossilized objects perforated recently, i.e., not modified by UC visitors and, as a consequence, they should be excluded from the UC ornament assemblage. Based on our reassessment, we therefore discard these two teeth from the following discussion.

\subsection{Ornamentation practices at Upper Cave}

In traditional societies, personal ornament types and their association and location on the body reflect the people's view of the world and the perceptions individuals have of their place in it (Kuper, 1973; Brain, 1979; Cordwell and Schwarz, 1979; Hodder, 1982; Carey, 1986; Kassam, 
1988; Preston-Whyte, 1994; Joyce, 2005; Hart et al., 2016). The raw material choice and provenience often indicate the symbolic link connecting people to matter, other living and imaginary beings, places and other human groups (Malinowski, 1922; Sharp, 1934; Dubbeldam, 1964; Turner, 1980; Hodder, 1989; Ogundiran, 2002; Sanders, 2002; Kuhn and Stiner, 2007; Casella, 2012). In an ornamental system dominated by animal teeth, such as the one observed at $\mathrm{UC}$, these objects signal the symbolic bond the group established with those species. In this respect, a number of species identified in the UC faunal assemblage by Pei (1940) have not been considered as suitable personal ornament providers by UC visitors. This is the case for wolf, bear, hyena, horse, bos/bison and Elephantidae. The large teeth size of the mammals considered as unsuitable ornament providers contradicts the hypothesis that their absence in the assemblage could result from taphonomic processes or recovery techniques. This indicates that UC visitors considered some of the species available in the environment, i.e., deer, badgers, foxes, mustelidae, and tiger, as befitting teeth providers to be used as ornaments. This conclusion is further supported when considering that the disregarded teeth were commonly used as personal ornaments in other contemporary Eurasian Paleolithic contexts (Goutas, 2004; Vanhaeren and d'Errico, 2006; d'Errico and Vanhaeren, 2015; Shunkov et al., 2020), which makes UC preferences even more compelling. It is equally interesting to note that all UC personal ornaments made of teeth belong to taxa found in the faunal assemblage. Thus, contrary to what has been observed at some Paleolithic sites from Europe (Giacobini and Malerba, 1995; Vanhaeren and d'Errico, 2005), there is no evidence at UC for ornamental use of teeth from species absent in the environment and acquired via long-distance exchange networks. The only objects attesting to probable exchanges over ca. $200 \mathrm{~km}$ are the marine bivalves. 
The preference was given to species rather than tooth types. The UC visitors used all fox and badger canines at their disposal irrespective of their anatomical position, i.e., upper versus lower, left versus right, or the age of the animal. Both stag and hind canines of all ages were used as personal ornaments. The relative overrepresentation of mature hinds is difficult to interpret owing to the small sample size. The overall pattern is consistent with a hunting strategy targeting both adult stags throughout the year and dominant individuals at the end of the rutting season as well as hinds of all ages throughout the year with a preference for old individuals (Vanhaeren and d'Errico, 2002).

A question that must be addressed when examining the proportions of personal ornament types at UC is to what extent they are representative of their importance in UC visitors' garments. Badger, fox, and red deer canines numerically dominate the picture, yet they are much larger than most other ornament types, i.e., red deer deciduous canine, sika deer incisors, marten canine, and stone beads, which are only represented by a few specimens. Although the very presence of these small objects and the recovery of small faunal remains by Pei collectively demonstrate that tiny items were retrieved during the 1933-1934 excavations, we have no means of establishing if and what material might have been overlooked. The discovery of small stone beads in the matrix attached to skull UC102 suggests small ornaments may have been lost. If this was not the case, it would indicate that the UC visitors who buried this individual in a layer sandwiched between L3 and L4 used substantially distinct garments and adornments from those who lost their beads in L2 and L4, in which small stone beads were not recovered. It is therefore probable that their similarity with natural items present in the layer, e.g., small stones, or the mesh size of the sieves prevented the full recovery of small items. In spite of these biases, the UC ornaments support the view that the human groups who frequented the site were wearing 
complex garments adorned with an association of ornaments that may have been instrumental to signal gender, age class and social status (Malinowski, 1922; Cordwell and Schwarz, 1979; Carey, 1986; Sanders, 2002; McAdam, 2008; Casella, 2012; McAdam and Davidson, 2018; Balme and O'Connor, 2019).

Additional information on the site visitors may be inferred from the technological analysis. On the aspect opposite to the ground facet, bidirectional incising is almost exclusively observed on perforated teeth from L4 and radial incising on teeth from L2. This change in technology doesn't depend on the tooth type as the two predominant techniques are seen on teeth of all species found in either layer. Therefore, it is clear the UC visitors changed their preferred method of perforating teeth through time. Application of other techniques in each layer, i.e., rotation and unidirectional incising, probably reflects individual variation either due to personal habits within the same group or accumulation in each layer of ornaments lost by members of different groups sharing to some degree the same cultural background. The stone beads from the matrix adhering to UC102 better fit the first hypothesis. Being associated with a possible burial, they would seem to reflect variation in the technology of ornaments worn by a single individual. These beads display differences in manufacture, in particular the degree of regularization of their edge, suggesting, in light of archaeological and ethnographic studies of OESBs (Kandel and Conard, 2005; Orton, 2008; Wei et al., 2017; d'Errico et al., 2020 and references therein), that their final shaping was not performed by the same person. Ethnographic studies show that variation in the final stages of OESB manufacture often reflects individual shaping habits (Backwell and d'Errico, 2021).

The rediscovered badger canines offer an opportunity to gather information otherwise unavailable from iconography and casts on the way some UC ornaments were manufactured and 
worn. Technologically, they have in common the production of a large ground facet but differ in the techniques (incision, rotation, whittling, gouging) and motions (unidirectional, radial) used to achieve the perforation. The abraded facet appears to be the only shared element in the bead manufacture, the perforation process being largely determined by individual variability. The idea that facets were produced by abrasion to stabilize the tooth on a surface before perforating it is contradicted by the fact that this technique is not applied to the hundreds of perforated teeth discovered at other prehistoric sites throughout Eurasia (e.g., Vanhaeren and d'Errico, 2006; Pitulko et al., 2012; d'Errivo and Vanhaeren, 2015). The most likely hypothesis is that this large facet ensured a large, secure contact with a cloth (Fig. 14). This hypothesis is reinforced by the presence of two shallow notches on either side of the perforation on the lingual aspect of the complete tooth, likely produced by the strings fixing the tooth to the cloth. The orientation and location of the ochre-filled micro-striations present on the facets of the three teeth are consistent with this interpretation. The sub-horizontal micro-striations detected below the perforation may have been produced by low amplitude oscillations of the tooth against a cloth surface coated with ochre. Striations present on either side of the perforation are the probable consequence of micromovements of the strings attaching the teeth to the cloth.

In sum, our results suggest that by combining several techniques, the UC visitors modified certain teeth, especially those from carnivores, to securely affix them on their clothing and cover them with ochre. It is possible, but currently difficult to verify, that smaller teeth featuring small perforations may have been incorporated into necklaces or bracelets. The relatively large number of specific teeth from targeted species, i.e., badger and fox canines, suggests these objects were positioned on clothing to create arrangements, e.g., single or multiple alignments, symmetries, and possibly associations responding to particular fashion codes. This 
has been frequently observed ethnographically (e.g., Speck, 1940; Taylor, 1994; Night Pipe, 2012) and likewise proposed for archaeological perforated teeth (Christiani et al., 2012; Larsson, 2012; Christiani et al., 2014; Trinkaus and Buzhilova, 2018). These garments were almost certainly instrumental in conveying information about the wearers' gender, age, and social status, as well as the ethnic group or subgroup.

Pei (1939) reports that red fragments, interpreted as 'oolitic hæmatites', were found throughout the sequence and ochre residues were found on objects. Our microscopic and elemental analyses of residues on rediscovered teeth reveal clear differences between the sediment sample still adhering to the root of the complete tooth and the red residues found around and inside the perforation on this and the other specimens. The former is coarser, only displays rare iron-rich particles, and lacks manganese in its composition. These differences imply that the red residues do not derive from UC sediments and were originally present on the teeth when they were lost or disposed at the site. It is clear that the ornaments were covered with ochre while being sewn on clothing, and, considering the amount of ochre adhering to them, that the clothing itself were heavily stained if not tanned with iron-rich compounds. Red residues from teeth 1 and 2 display a similar composition but a different granulometry, which may either reflect lateral or vertical variation in the ochre source or in the ochre preparation process. A difference is instead observed between the residues from these two teeth and tooth 3 . The latter has a slightly different color and lacks titanium in its composition. The ubiquitous presence of titanium and the polymetallic nature of the ochre from teeth 1 and 2 may be diagnostic of a common clay source (Bain, 1976). Interestingly, the difference in ochre composition corresponds to distinct perforation techniques on the lingual aspect, with incision being applied on teeth 1 and 2 , and gouging followed by rotation on tooth 3 . The application of ochre of different composition to 
ornaments manufactured with distinct techniques reinforces the hypothesis that the UC ornaments were produced by different individuals, a pattern already observed when analyzing ochre-stained OESBs from Shuidonggou Locality 2 (Pitarch Martí et al., 2017).

\subsection{Personal ornaments and Late Pleistocene population dynamics in Northern China}

The seriation of Northern Chinese Late Pleistocene personal ornaments provides the opportunity to explore this record at a regional level. Previous work (Bar-Yosef and Wang, 2012; Qu et al., 2013; Song and Shi, 2013; Li et al., 2014; Wei et al., 2016) has already highlighted diachronic and geographic differences in raw material and technology, interpreted by some as the possible reflection of distinct cultural traditions or cultural changes over time. Although the available data are limited, seriation is a powerful tool to place cultural phenomena in linear order on the basis of their similarity to one another and to make inferences on culture-historical trajectories (Lyman and O'Brien, 2006; O'Brien et al., 2008).

Our seriation identifies a clear-cut difference in preferred ornament types between sites roughly located east and west of the $112^{\circ} \mathrm{E}$ longitude, as well as a chronological continuity encompassing the period between 40 and $10 \mathrm{ka}$ in the West, and a shorter timespan, 40 to $25 \mathrm{ka}$, during which different ornament types were used in the East. Seriation, however, or any other multivariate analysis to which archaeological data may be subjected, does not disclose, in and of itself, the factor or factors that have shaped the resulting pattern (Shennan, 2009; García Rivero, 2016; Straffon, 2019). It has been cautioned that continuity or regionalization of environmental conditions, convergent evolution and particular artifact functions may constitute main drivers of these trends (Lyman and O'Brien, 2006; Shennan, 2009). Also, what we perceive as gradual 
change may hide a more complex cultural evolution with new variants representing branches of an undetected evolutionary tree that can possibly split, and join together again, producing complex patterns of hybridization (Collard and Tehrani, 2005; Greenhill et al., 2009).

In our case, however, it is difficult to attribute the pattern emerging from the seriation to differences in the environmental conditions of these regions or to changes through time in those conditions. Mammal teeth, among which those of many species present in the UC faunal assemblages and other sites from the same cluster located in the East, were available in western regions in which Paleolithic people preferred to wear OESBs and freshwater shells (Norton et al., 2011). Likewise, ostriches were present during the Late Pleistocene in the region comprising the UC cluster (Janz et al., 2009) and freshwater shells were certainly present in lakes and rivers; faunal and isotopic data indeed suggest prehistoric groups exploited the resources available in water bodies located in the vicinity of Zhoukoudian (e.g., Hu et al., 2009). Yet, neither OES nor freshwater shell was selected to produce ornaments by people occupying the eastern region between 40 and $25 \mathrm{ka}$. The contrast between the two clusters is particularly striking when one considers that UC visitors had the know-how for producing small circular beads, as demonstrated by the stone beads of this morphology found close to skull UC102, and featuring the same technology applied to the production of OESBs. The use at UC of marine shells collected from shores located more than $200 \mathrm{~km}$ away from the site further reinforces the idea that UC visitors would have been able to acquire, either by direct collection or through exchange, desirable materials to make ornaments if they considered that displaying them on their garments as elements of adornments was required (Vanhaeren, d'Errico, 2006; Bar-Yosef Mayer, 2020). They would certainly have been able to collect ostrich eggs or, if in short supply, find fossilized eggs in the environment, if using beads made of this raw material was needed. Therefore, owing 
to the symbolic role or, at least not strictly utilitarian nature, of objects used by traditional societies for display on the body (Hahn, 1972; Brain, 1979; Cordwell and Schwarz, 1979; Kassam, 1988; Newell et al., 1990; Sanders, 2002; Kuhn and Stiner, 2007; McAdam, 2008; Casella, 2012; Hart et al., 2016; McAdam and Davidson, 2018), the dichotomy between the two clusters cannot be explained by functional reasons.

The most parsimonious interpretation for the identified clusters is that they reflect two different cultural traditions, defined here as a body of knowledge and associated practices transmitted within a group or a society. The main difference between the two cultural systems is that the western tradition apparently lasted much longer than the eastern one and was characterized, as far as durable ornamentation is concerned, by the persistent use of the same small selection of ornament types, which suggests a very limited cultural drift. At the end of the Late Paleolithic, sites such as Lingjing, layer 5, where OESs were transformed into pendants rather than circular beads, may well reflect regional diversification occurring in the western tradition. Likewise, the presence of OESBs and their association with stone beads, bone tubes and bone pendant at the Hutouliang site complex, which includes Yujiagou and is geographically located among the sites belonging to the eastern tradition, may reflect processes of cultural exchange or eastward migration of the human groups carrying a branching variant of the western tradition.

Key questions concerning these traditions are, of course, where do they come from and why the eastern tradition seems to disappear from the archaeological record $25 \mathrm{ka}$, while the region remains occupied throughout the Late Paleolithic (Bae et al., 2018; Yue et al., 2021). Although it is probably too soon to conclude they both represent intrusive phenomena, perforated mammal teeth and bone tubes are present at apparently older Siberian sites (Rybin, 2015; 
Shunkov et al., 2020; Lbova, 2021). OESBs covered with ochre have also been discovered, even if not in great numbers, at older or contemporaneous Siberian sites; in some instances, in association with perforated mammal teeth, bone tubes and other ornament types (Shunkov et al., 2020). This evidence is consistent with the hypothesis that the two ornamental traditions identified in Northern China result from a branching process taking its origin in Siberia. Establishing whether such possible branching entailed cultural or demic diffusion is problematic due to the undiagnostic character of the lithic industries associated with both Northern Chinese ornament traditions. The direct dating of Homo sapiens remains from Tianyuan Cave, attesting to the presence of modern humans in Northern China at $42 \mathrm{ka}$ (Shang et al., 2007), implies that, if confirmed, such demic diffusion occurred shortly after the arrival of modern human populations in Siberia (Kuzmin et al., 2021). Aside from the Hutouliang site complex which yielded OESBs associated with stone and bone pendants, the relative absence of sites younger than $25 \mathrm{ka}$ and belonging to the eastern tradition may certainly be due to the fact that these sites exist but have yet to be found. The small number of sites discovered so far makes this possibility quite probable. However, this absence could also indicate that the groups carrying this tradition have either died out, adopted alternative modes of personal ornamentation that remain to be documented archaeologically, or migrated elsewhere and were replaced by human groups that made and wore ornaments belonging to a different tradition and perhaps left little trace of themselves in the archaeological record.

Although fragmentary, the available information on the genetic diversity of Eastern and Northeastern Asia from 40 ka onward (Fu et al., 2013; Yang et al., 2017; Sikora et al., 2019; Massilani et al., 2020; Mao et al., 2021) is consistent with the trends highlighted by ornaments and the scenario we inferred from them. Genomic analysis of human remains found at the site of 
Salkhit, Northeastern Mongolia (Massilani et al., 2020), and Tianyuan, another locality comprised in the Zhoukoudian site complex (Fu et al., 2013; Yang et al., 2017), indicates that differences in ornament types may reflect penecontemporaneous population structure. These human remains date from around $34 \mathrm{ka}$ and $40 \mathrm{ka}$ respectively, the approximate time period of the earliest ornaments found in East Asia, and come from sites located in the two regions identified by our seriation as belonging to two different cultural traditions. Comparison of the genetic data of these two individuals reveals an interesting boundary effect. Both individuals carry genome segments indicating admixture with the same Denisovan population, different from the one that have contributed to the genome of present-day Australasians. However, the Salkhit individual was a member of a population that experienced, prior to $34 \mathrm{ka}$, substantial gene flow from West Eurasians. Such a gene flow, the traces of which are still detected in the genome of a contemporaneous individual from the site of Yana RHS, Northeastern Siberia (Sikora et al., 2019), impacted the Tianyuan population to a much lesser extent. The ornament type association identified as the western tradition could represent the archaeological signature of the Salkhit population, carrying western Eurasian genes, and the eastern tradition representing the Tianyuan population. Future research will need to contrast the ornament and genomic datasets to establish whether, and to what extent, the cultural geography and chronology highlighted by the ornaments match population dynamics identified by genetic data.

\section{Conclusions}

Our study of Pei's iconography and available casts allowed us to verify, and in some cases refine or modify, the taxonomic attribution of the mammalian teeth and invertebrates used 
to produce personal ornaments. Our study also allowed us to specify in many cases the anatomical position of the teeth, and identify in some instances the sex and age of the animals from which the teeth came. In addition, we were able to show that the relative temporal continuity in the choice of teeth and other media to make personal ornaments was in fact associated with a change in the technical processes chosen to modify the teeth. This trend is consistent with the hypothesis that, if cultural drift introduced variation in UC visitors' ornamental traditions, it was mostly expressed in the technology rather than in the symbolic framework that governed the choice of raw material transformed into beads.

The seriation of Upper Paleolithic personal ornament assemblages from Northern China identifies two regionally distinct traditions. If and when they came in contact, their bearers would have easily recognized each other as carriers of distinct traditions from the garments they wore. It is reasonable to assume these differences in appearance helped reinforce the individuals' sense of belonging to either group and to structure these populations.

\section{Acknowledgments}

We wish to thank Anna Rufà Bonache for sharing information on bird bone taphonomy. We thank Dominique Armand and Markus Lussi for helping with the species identification. This work was supported by the Strategic Priority Research Program of the Chinese Academy of Sciences (Grant No. XDB26000000), the National Social Science Foundation of China (Grant No. 19CKG003), the Sino-French PHC Cai Yuanpei program (Grant No. 36707NF), the Zhengzhou University’s Research into the Root of Chinese Civilization Grant (Grant No. XKZDJC202006), the Programme Talents (Grant No. 191022-001), and the Grand Programme de Recherche 'Human Past' of the Initiative d'Excellence, Bordeaux University, the Research 
Council of Norway through its Centre's of Excellence funding scheme, Senter for fremragende forskning (SFF) Centre for Early Sapiens Behaviour, SapienCE (Project No. 262618), the SinoFrench PHC Xu Guangqi (Grant No. 41230RB), and the Beatriu de Pinós postdoctoral program (Grant Nos. 2014 BP-A 00122; 2017 BP-A 00046), the Consolidated Research group program

(Grant No. 2017 SGR 00011) of the Secretariat for Universities \& Research of the Ministry of Economy and Knowledge, Government of Catalonia, the R\&D program from the Spanish Ministry of Science, Innovation and Universities (Project No. PID2020-113960GB-I00) and the Serra Húnter program. PACEA (UMR5199 CNRS) is a Partner team of the Labex LaScArBxANR (Program No. ANR-10-LABX-52). The funders had no role in the study design, data collection and analysis, decision to publish, or preparation of the manuscript.

\section{References}

An, Z.M., 1965. Test excavation at Xiaonanhai, a Paleolithic cave site in Anyang, Henan. Kaogu Xuebao 1, 1-27.

Arrighi, S., Moroni, A., Tassoni, L., Boschin, F., Badino, F., Bortolini, E., Boscato, P., Crezzini, J., Figus, C., Forte, M., Lugli, F., Marciani, G., Oxilia, G., Negrino, F., Riel-Salvatore, J., Romandini, M., Peresani, M., Spinapolice, E.E., Ronchitelli, A., Benazzi, S., 2020. Bone tools, ornaments and other unusual objects during the Middle to Upper Palaeolithic transition in Italy. Quat. Int. 551, 169-187.

Backwell, L.R., d'Errico, F., 2021. San Elders Speak: Ancestral Knowledge of the Kalahari San. Wits University Press, Johannesburg. 
Bae, C.J., Wang, W., Zhao, J., Huang, S., Tian, F., Shen, G., 2014. Modern human teeth from Late Pleistocene Luna Cave (Guangxi, China). Quat. Int. 354, 169-183.

Bae, C.J., Li, F., Cheng, L., Wang, W., Hong, H., 2018. Hominin distribution and density patterns in Pleistocene China: Climatic influences. Palaeogeogr. Palaeoclimat. Palaeoecol. 512, 118-131.

Bain, D.C., 1976. A Titanium-rich soil clay. J. Soil Sci. 27, 68-70.

Balme, J., O’Connor, S., 2019. Bead making in Aboriginal Australia from the deep past to European arrival: Materials, methods, and meanings. PaleoAnthropology 177-195.

Bar-Yosef Mayer, D.E. 2020. Shell beads of the Middle and Upper Palaeolithic: A review of the earliest record. In: Mărgărit, M. and Boroneanţ, A. (eds.). Beauty and the Eye of the Beholder: Personal Adornments Across the Millennia. Cetatea de scaun, Târgovişte, pp. $11-25$.

Bar-Yosef Mayer, D.E., Groman-Yaroslavski, I., Bar-Yosef, O., Hershkovitz, I., KampenHasday, A., Vandermeersch, B., Zaidner, Y., Weinstein-Evron, M., 2020. On holes and strings: Earliest displays of human adornment in the Middle Palaeolithic. PLoS One 15, e0234924.

Bar-Yosef, O., Wang, Y., 2012. Paleolithic archaeology in China. Annu. Rev. Anthropol. 41, 319-335.

Bergström, A., Stringer, C., Hajdinjak, M., Scerri, E.M.L., Skoglund, P., 2021. Origins of modern human ancestry. Nature 590, 229-237.

Berkovitz, B.K.B., Shellis, R.P., 2018. The Teeth of Mammalian Vertebrates $-1^{\text {st }}$ Edition. Academic Press, Cambridge. 
Bernard, F.R., Cai, Y.-Y., Morton, B., 1993. A Catalogue of the Living Marine Bivalve Molluscs of China. Hong Kong University Press, Hong Kong.

Bosch, M.D., Buck, L., Strauss, A., 2019. Location, location, location: Investigating perforation locations in Tritia gibbosula shells at Ksâr 'Akil (Lebanon) using micro-CT data. PaleoAnthropology 52-63.

Bouzouggar, A., Barton, N., Vanhaeren, M., d'Errico, F., Collcutt, S., Higham, T., Hodge, E., Parfitt, S., Rhodes, E., Schwenninger, J.-L., Stringer, C., Turner, E., Ward, S., Moutmir, A., Stambouli, A., 2007. 82,000-year-old shell beads from North Africa and implications for the origins of modern human behavior. Proc. Natl. Acad. Sci. USA 104, 9964-9969.

Brain, R., 1979. The Decorated Body. Hutchinson, London.

Brooks, A.S., Yellen, J.E., Potts, R., Behrensmeyer, A.K., Deino, A.L., Leslie, D.E., Ambrose, S.H., Ferguson, J.R., d’Errico, F., Zipkin, A.M., Whittaker, S., Post, J., Veatch, E.G., Foecke, K., Clark, J.B., 2018. Long-distance stone transport and pigment use in the earliest Middle Stone Age. Science 360, 90-94.

Cârciumaru, M., Niţu, E.-C., Obadă, T., Cîrstina, O., Covalenco, S., Lupu, F.I., Leu, M., Nicolae, A., 2019. Personal ornaments in the Mid Upper Palaeolithic east of the Carpathians. PALEO 30, 80-97.

Carey, M., 1986. Beads and Beadwork of East and South Africa. Shrire, Aylesbury. Casella, E.C., 2012. "That's just a family thing, you know": Memory, community kinship, and social belonging in the Hagg Cottages of Cheshire, North-West England. Int. J. Hist. Archaeol. 16, 284-299. 
Castro, K., Pérez-Alonso, M., Rodríguez-Laso, M.D., Fernández, L.A., Madariaga, J.M., 2005. On-line FT-Raman and dispersive Raman spectra database of artists' materials (eVISART database). Anal. Bioanal. Chem. 382, 248-258.

Chen, T., Zhang, Y., 1991. Palaeolithic chronology and possible coexistence of Homo erectus and Homo sapiens in China. World Archaeol. 23, 147-154.

Chen, T., Hedges, R.E.M., Yuan, Z., 1989. Accelerator radiocarbon dates for Upper Cave of Zhoukoudian. Acta Anthropol. Sin. 8, 216-221.

Chen, T., Yuan, S., Gao, S., 1984. The study of uranium-series dating of fossil bones and an absolute age sequence for the main Paleolithic sites of North China. Acta Anthropol. Sin. $3,259-269$.

Chen, T., Hedges, R.E.M., Yuan, Z., 1992. The second batch of accelerator radiocarbon dates for Upper Cave site of Zhoukoudian. Acta Anthropol. Sin. 11, 112-116.

Christiani, E., Borić, D., 2012. 8500-year-old Late Mesolithic garment embroidery from Vlasac (Serbia): Technological, use-wear and residue analyses. J. Archaeol. Sci. 39, 3450-3469.

Christiani, E., Živaljević, I., Borić, D., 2014. Residue analysis and ornament suspension techniques in prehistory: Cyprinid pharyngeal teeth beads from Late Mesolithic burials at Vlasac (Serbia). J. Archaeol. Sci. 46, 292-310.

Clark, J.D., Aitken, M.J., Stringer, C.B., Mellars, P.A., 1992. African and Asian perspectives on the origins of modern humans. Philos. Trans. R. Sci. Lond. B Biol. Sci. 337, 201-215.

Collard, M., Tehrani J.J., 2005. Phylogenesis versus ethnogenesis in Turkmen cultural evolution. In: Mace, R., Holden, C.J., Shennan, S.J. (Eds.), The Evolution of Cultural Diversity: A Phylogenetic Approach. Routledge, New York, pp. 109-131. 
Conti, C., Striova, J., Aliatis, I., Colombo, C., Greco, M., Possenti, E., Realini, M., Brambilla, L., Zerbi, G., 2013. Portable Raman versus portable mid-FTIR reflectance instruments to monitor synthetic treatments used for the conservation of monument surfaces. Anal. Bioanal. Chem. 405, 1733-1741.

Cordwell, J.M., Schwarz, R.A. (Eds.), 1979. The Fabrics of Culture. The Anthropology of Clothing and Adornment. Mouton, Paris.

Cunningham, D.L., Jantz, R.L., 2003. The morphometric relationship of Upper Cave 101 and 103 to modern Homo sapiens. J. Hum. Evol. 45, 1-18.

Cunningham, D.L., Wescott, D.J., 2002. Within-group human variation in the Asian Pleistocene: The three Upper Cave crania. J. Hum. Evol. 42, 627-638.

Curnoe, D., Li, H.C., Zhou, B.Y., Sun, C., Du, P.X., Wen, S.Q., Sun, X.F., Li, H., 2021. Reply to Martinón-Torres et al. and Higham and Douka: Refusal to acknowledge dating complexities of Fuyan Cave strengthens our case. Proc. Natl. Acad. Sci. USA 118, e2104818118.

Cvitkušić, B., 2017. Upper Palaeolithic and Mesolithic ornamental traditions in the Eastern Adriatic Coast and Hinterland. Coll. Antropol. 41, 45-59.

d'Errico, F., 1998. Palaeolithic origins of artificial memory systems: An evolutionary perspective. In: Renfrew, C., Scarre, C. (Eds.), Cognition and Material Culture: The Archaeology of Symbolic Storage. McDonald Institute for Archaeological Research, Cambridge, pp. 19-50.

d'Errico, F., Rigaud, S., 2011. Crache perforée dans le Gravettien du Sire (Mirefleurs, Puy-deDôme). Étude archéozoologique, technologique et fonctionnelle. PALEO 22, 301-310. 
d'Errico, F., Vanhaeren, M., 2002. Criteria for identifying red deer (Cervus elaphus) age and sex from their canines. Application to the study of Upper Palaeolithic and Mesolithic ornaments. J. Archaeol. Sci. 29, 211-232.

d'Errico, F., Vanhaeren, M., 2015. Upper Palaeolithic mortuary practices: Reflection of ethnic affiliation, social complexity and cultural turn over. In: Renfrew, C., Boyd, M.J., Morley, I. (Eds.), Death Shall Have No Dominion. Cambridge University Press, Cambridge, pp. $45-61$.

d'Errico, F., Jardón-Giner, P., Soler-Mayor, B., 1993. Critères à base expérimentale pour l'étude des perforations naturelles et intentionnelles sur coquillages. In: Anderson, P.C., Beyries, S., Otte, M., Plisson, H. (Eds.), Traces et Fonction: Les Gestes Retrouvés. Colloque International de Liège. Éditions ERAUL, Liège, pp. 243-254.

d'Errico, F., Vanhaeren, M., Queffelec, A., 2017. Les galets perforés de Praileaitz I (Deba, Gipuzkoa). In: Peñalver, X., San Jose, S., Mujika-Alustiza, J.A. (Eds.), La Cueva de Praileaitz I (Deba, Gipuzkoa, Euskal Herria). Intervención Arqueológica 2000-2009. Sociedad de Ciencias ARANZADI Zientzia Elkartea, Donostia, pp. 453-484.

d'Errico, F., Doyon, L., Zhang, S., Baumann, M., Lázničková-Galetová, M., Gao, X., Chen, F., Zhang, Y., 2018. The origin and evolution of sewing technologies in Eurasia and North America. J. Hum. Evol. 125, 71-86.

d'Errico, F., Pitarch Martí, A., Shipton, C., Le Vraux, E., Ndiema, E., Goldstein, S., Petraglia, M.D., Boivin, N., 2020. Trajectories of cultural innovation from the Middle to Later Stone Age in Eastern Africa: Personal ornaments, bone artifacts, and ocher from Panga ya Saidi, Kenya. J. Hum. Evol. 141, 102737. 
de Faria, D.L.A., Venâncio Silva, S., de Oliveira, M.T., 1997. Raman microspectroscopy of some iron oxides and oxyhydroxides. J. Raman Spectrosc. 28, 873-878.

de Lumley, H., Audubert, F., Khatib, S., Perrenoud, C., Roussel, B., Saos, T., Szelawa, A., 2016. Les crayons d'ocre du site acheuléen de Terra Amata. In: de Lumley, H. (Ed.), Terra Amata, Nice, Alpes-Maritimes, France. Tome V. Éditions du CNRS, Paris, pp. 233-277. David, É., 2004. Transformation des matières dures d'origine animale dans le Mésolithique de l'Europe du Nord.' In: Ramseyer, D. (Ed.), Fiches Typologiques de l'Industrie Osseuse Préhistorique. Cahier XI Matières et Techniques. Société Préhistorique Française, Paris, pp. 113-149.

Dennell, R., Martinón-Torres, M., Bermúdez de Castro, J.-M., Xing, G., 2020. A demographic history of Late Pleistocene China. Quat. Int. 559, 4-13.

Dubbeldam, L.F.B., 1964. The devaluation of the Kapauku-Cowrie as a factor of social disintegration. Am. Anthropol. 66, 293-303.

Fu, Q., Meyer, M., Gao, X., Stenzel, U., Burbano H.A., Kelso, J., Pääbo, S., 2013. DNA analysis of an early modern human from Tianyuan cave, China. Proc. Natl. Acad. Sci. USA 110, $2223-2227$.

Gai, P., Wei, Q., 1977. Discovery of the Late Palaeolithic site of Hutouliang, Hebei. Verteb. PalAsiatica 15, 287-302.

García Rivero, D., 2016. Darwinian archaeology and cultural phylogenetics. In: Mendoza Straffon, L. (Ed.), Cultural Phylogenetics: Concepts and Applications in Archaeology. Springer, Cham, pp. 43-72.

Giacobini, G., Malerba, G., 1995. Les pendeloques en ivoire de la sépulture paléolithique du "Jeune Prince" (Grotte de Arene Candide, Finale Ligure, Italie). In: Hahn, J., Menu, M., 
Taborin, Y., Walter, Ph., Widemann, F. (Eds.), Le Travail et l'Usage de l'Ivoire au Paléolithique Supérieur. Centro Universitario Europeo per i Beni Culturali, Rome, pp. $173-187$.

Goutas, N., 2004. Étude de la parure sur coquillages, dents animales et ivoire des niveaux gravettiens du gisement de la Gravette (Dordogne): Charge identitaire et souplesse des normes techniques. Antiquités Nationales 36, 39-51.

Greenhill, S.J., Currie, T.E., Gray, R.D., 2009. Does horizontal transmission invalidate cultural phylogenies? Proc. R. Soc. Lond. B Biol. Sci. 276, 2299-2306.

Hahn, J., 1972. Aurignacian signs, pendants and art objects in Central and Eastern Europe. World Archaeol. 3, 252-266.

Hammer, Ø., Harper, D.A.T., Ryan, P.D., 2001. PAST: Paleontological statistics software package for education and data analysis. Palaeontol. Electronica 4, 1-9.

Hart, J.P., Shafie, T., Birch, J., Dermarkar, S., Williamson, R.F., 2016. Nation building and social signaling in Southern Ontario: A.D. 1350-1650. PLoS One 11, e0156178.

Henshilwood, C.S., d'Errico, F., 2005. Being modern in the Middle Stone Age. In: Gamble, C., Porr, M. (Eds.), The hominid individual in context. Archaeological investigations of Lower and Middle Palaeolithic landscapes, locales and artefacts. Routledge, New York, pp. $244-264$.

Higham, T.F.G., Douka, K., 2021. The reliability of late radiocarbon dates from the Paleolithic of Southern China. Proc. Natl. Acad. Sci. USA 118, e2103798118.

Hodder, I., 1982. Symbols in Action: Ethnoarchaeological Studies of Material Culture. Cambridge University Press, Cambridge. 
Hodder, I., 1989. The Meanings of Things. Material Culture and Symbolic Expression. Routledge, London.

Hu, Y., Shang, H., Tong, H., Nehlich, O., Liu, W., Zhao, C., Yu, J., Wang, C., Trinkaus, E., Richards, M.P., 2009. Stable isotope dietary analysis of the Tianyuan 1 early modern human. Proc. Natl. Acad. Sci. USA 106, 10971-10974.

Huang, W.W., Zhang, Z.H., Fu, R.Y., Chen, B.F., Liu, J.Y., Zhu, M.Y., Wu, H.K., 1986. Bone artifacts and ornaments from Xiaogushan site of Haicheng, Liaoning Province. Acta Anthropol. Sin. 5, 259-266.

Janz, L., Elston, R.G., Burr, G.S., 2009. Dating North Asian surface assemblages with ostrich eggshell: Implications for palaeoecology and extirpation. J. Archaeol. Sci. 36, 19821989.

Jia, L., You, Y.Z., Gai, P., 1972. The report of excavation at Shiyu, a Paleolithic site in Shanxi. Kaogu Xuebao 1, 39-58.

Joyce, R.A., 2005. Archaeology of the body. Annu. Rev. Anthropol. 34, 139-158.

Kandel, A.W., Conard, N.J., 2005. Production sequences of ostrich eggshell beads and settlement dynamics in the Geelbek Dunes of the Western Cape, South Africa. J. Archaeol. Sci. 32, 1711-1721.

Kassam, A., 1988. Traditional ornament: Some general observations. Kenya Past Pres. 20, 1116.

Kealy, S., Louys, J., O’Connor, S., 2016. Islands under the sea: A review of early modern human dispersal routes and migration hypotheses through Wallacea. J. Island Coast. Archaeol. $11,364-384$. 
Kloprogge, J.T., Frost, R.L., 2000. Raman microscopy as a non-destructive method for the analysis of minerals. In: Williams, D., Shimizu, R. (Eds.), Microbeam Analysis. Proceedings of the International Conference on Microbeam Analysis, 8-15 July, 2000. CRC Press, Boca Raton, pp. 89-90.

Košařová, V., Hradil, D., Němec, I., Bezdička, P., Kanický, V., 2013. Microanalysis of claybased pigments in painted artworks by the means of Raman spectroscopy. J. Raman Spectrosc. 44, 1570-1577.

Kuhn, S.L., Stiner, M.C., 2007. Paleolithic ornaments: Implications for cognition, demography and identity. Diogenes 54, 40-48.

Kuper, H., 1973. Costume and identity. Comp. Stud. Soc. Hist. 15, 348-367.

Kuzmin, Y.V., Slavinsky, V.S., Tsybankov, A.A., Keates, S.G., 2021. Denisovans, Neanderthals, and early modern humans: A review of the Pleistocene hominin fossils from the Altai Mountains (Southern Siberia). J. Archaeol. Res. https://doi.org/10.1007/s10814-02109164-2.

Lafuente, B., Downs, R.T., Yang, H., Stone, N., 2016. 1. The power of databases: The RRUFF project. In: Armbruster, T., Danisi, R.M. (Eds.), Highlights in Mineralogical Crystallography. Walter De Gruyter GmbH, Berlin, pp. 1-30.

Langley, M.C., O’Connor, S., Piotto, E., 2016. 42,000-year-old worked and pigment-stained Nautilus shell from Jerimalai (Timor-Leste): Evidence for an early coastal adaptation in ISEA. J. Hum. Evol. 97, 1-16.

Langley, M.C., Clarkson, C., Ulm, S., 2019. Symbolic expression in Pleistocene Sahul, Sunda, and Wallacea. Quat. Sci. Rev. 221, 105883. 
Langley, M.C., Amano, N., Wedage, O., Deraniyagala, S., Pathmalal, M.M., Perera, N., Boivin, N., Petraglia, M.D., Roberts, P., 2020. Bows and arrows and complex symbolic displays 48,000 years ago in the South Asian tropics. Sci. Adv. 6, eaba3831.

Laroulandie, V., d'Errico, F., 2004. Worked bones from Buran-Kaya III level C and their taphonomic context. In: Chabai, V.P., Monigal, K., Marks, A.E. (Eds.), The Middle Paleolithic and Early Upper Paleolithic of Eastern Crimea. ERAUL, Liège, pp. 83-94.

Larsson, L., 2012. The Embellished dress in hunter-gatherer societies. Tooth ornaments from the graves at the cemeteries of Zvejnieki, northern Latvia. Archaeol. Text. Rev. 54, 44-51.

Lbova, L., 2021. Personal ornaments as markers of social behavior, technological development and cultural phenomena in the Siberian early Upper Paleolithic. Quat. Int. 573, 4-13.

Li, F., Kuhn, S.L., Olsen, J.W., Chen, F.Y., Gao, X., 2014. Disparate Stone Age technological evolution in North China. Lithic technological variability and relations between populations during MIS3. J. Anthropol. Res. 70, 35-67.

Li, F., Bae, C.J., Ramsey, C.B., Chen, F., Gao, X., 2018. Re-dating Zhoukoudian Upper Cave, Northern China and its regional significance. J. Hum. Evol. 121, 170-177.

Li, F., Kuhn, S.L., Bar-Yosef, O., Chen, F.Y., Peng, F., Gao, X. 2019. History, chronology and techno-typology of the Upper Paleolithic sequence in the Shuidonggou area, Northern China. J. World Prehist. 32, 111-141.

Li, Z., Doyon, L., Fang, H., Ledevin, R., Queffelec, A., Raguin, E., d'Errico, F., 2020. A Paleolithic bird figurine from the Lingjing site, Henan, China. PLoS One 15, e0233370. Liu, W., Martinón-Torres, M., Cai, Y., Xing, S., Tong, H., Pei, S., Sier, M.J., Wu, Xiao-hong, Edwards, R.L., Cheng, H., Li, Y., Yang, X., de Castro, J.M.B., Wu, Xiu-jie, 2015. The earliest unequivocally modern humans in Southern China. Nature 526, 696-699. 
Lyman, R.L., O’Brien, M.J., 2006. Seriation and cladistics: The difference between anagenetic and cladogenetic evolution. In: Shennan, S. (Ed.), Mapping Our Ancestors. Phylogenetic Approaches in Anthropology and Prehistory. Routledge, New York, pp. 65-88.

Malinowski, B., 1922. Argonauts of the Western Pacific. Routledge, London.

Mao, X., Zhang, H., Qiao, S., Liu, Y., Chang, F., Xie, P., Zhang, M., Wang, T., Li, M., Cao, P., Yang, R., Liu, F., Dai, Q., Feng, X., Ping, W., Lei, C., Olsen, J.W., Bennett, E.A., Fu, Q., 2021. The deep population history of Northern East Asia from the Late Pleistocene to the Holocene. Cell 184, 3256-3266.e13.

Martinón-Torres, M., Cai, Y., Tong, H., Pei, S., Xing, S., Bermúdez de Castro, J.M., Wu, X., Liu, W., 2021. On the misidentification and unreliable context of the new 'human teeth' from Fuyan Cave (China). Proc. Natl. Acad. Sci. USA 118, e210296118.

Massilani, D., Skov, L., Hajdinjak, M., Gunchinsuren, B., Tseveendorj, D., Yi, S., Lee, J., Nagel, S., Nickel, B., Devièse, T., Higham, T., Meyer, M., Kelso, J., Peter, B.M., Pääbo, S., 2020. Denisovan ancestry and population history of early East Asians. Science 370, 579 583.

McAdam, L.E., 2008. Beads across Australia: An ethnographic and archaeological view of the patterning of Aboriginal ornaments. Ph.D. Dissertation, University of New England.

McAdam, L.E., Davidson, I., 2018. Beads and boundaries. In: Langley, M.C., Lister, M., Wright, D., May, S.K. (Eds.), The Archaeology of Portable Art. Routledge, London, pp. 220-240.

Mei, H.J., 2007. Transition from Paleolithic to Neolithic in the Nihewan Basin: A study of the discoveries from Yujiagou site. Ph.D. Dissertation, Peking University.

Mellars, P., 2006a. Going East: New genetic and archaeological perspectives on the modern human colonization of Eurasia. Science 313, 796-800. 
Mellars, P., 2006b. Why did modern human populations disperse from Africa ca. 60,000 years ago? A new model. Proc. Natl. Acad. Sci. USA 103, 9381-9386.

Milardi, M., Lanzoni, M., Kiljunen, M., Tornaiainen, J., Castaldelli, G., 2015. Natural recruitment contributes to high densities of grass carp Ctenopharyngodon Idella (Valenciennes, 1844) in Western Europe. Aquat. Invasions 10, 439-448.

Newell, R.R., Kielman, D., Constandse-Westermann, T.S., van der Sanden, W.A.B., van Gijn, A., 1990. An Inquiry Into the Ethnic Resolution of Mesolithic Regional Groups. The Study of Their Decorative Ornaments in Time and Space. E.J. Brill, Leiden.

Niekus, M.J.L.Th., Amkreutz, L.W.S.W., 2021. Facts, fakes and fantasy: A critical review of Upper and Late Palaeolithic engravings, perforated objects and personal ornaments from the Netherlands. Quat. Int. 573, 75-91.

Night Pipe, M.L., 2012. Displays of personal adornment and body decoration by Nineteenth Century Lakota (Sioux) tribes: A costly signaling model. Master's Thesis, University of Nebraska.

Norton, C.J., Gao, X., 2008. Zhoukoudian Upper Cave revisited. Curr. Anthropol. 49, 732-745. Norton, C.J., Jin, J.J.H., 2009. The evolution of modern human behavior in East Asia: Current perspectives Evol. Anthropol. 18, 247-260.

Norton, C.J., Jin, C., Wang, Y., Zhang, Y., 2011. Rethinking the Palearctic-Oriental biogeographic boundary in Quaternary China. In: Norton, C.J., Braun, D.R. (Eds.), Asian Paleoanthropology: From Africa to China and Beyond. Springer, Dordrecht, pp. 81-100.

O’Brien, M.J., Lyman, R.L., Collard, M., Holden, C.J., Gray, R.D., Shennan, S.J., 2008. Transmission, phylogenetics, and the evolution of cultural diversity. In: O’Brien, M.J. 
(Ed.), Cultural Transmission and Archaeology: Issues and Case Studies. The Society for American Archaeology Press, Washington, D.C., pp. 39-58.

Ogundiran, A., 2002. Of small things remembered: Beads, cowries, and cultural translations of the Atlantic experience in Yorubaland. Int. J. Afr. Hist. Stud. 35, 427-457.

Orton, J., 2008. Later Stone Age ostrich eggshell bead manufacture in the Northern Cape, South Africa. J. Archaeol. Sci. 35, 1765-1775.

Pales, L., Garcia, M.A., 1981a. Atlas Ostéologique Pour Servir à l’Identification des Mammifères du Quaternaire. II. Tête, Rachis, Ceintures Scapulaire et Pelvienne. Carnivores, Homme. Éditions du CNRS, Paris.

Pales, L., Garcia, M.A., 1981b. Atlas Ostéologique Pour Servir à l'Identification des Mammifères du Quaternaire. II. Tête, Rachis, Ceintures Scapulaire et Pelvienne. Herbivores. Éditions du CNRS, Paris.

Pei, J.X., 1985. Thermoluminescence dating of the Peking Man site and other caves. In: Wu, R.K., Ren, M.E., Zhu, X.M. (Eds.), Multi-Disciplinary Study of the Peking Man Site. Science Press, Beijing, pp. 256-260.

Pei, W.C., 1934. A preliminary report on the Late Palaeolithic cave of Choukoutien. Acta Geol. Sin. $13,327-358$.

Pei, W.C., 1939. The Upper Cave industry of Choukoutien. Palaeontol. Sin. Ser. D 9, 1-58.

Pei, W.C., 1940. The Upper Cave fauna of Choukoutien. Palaeontol. Sin. Ser. C. 10, 1-96.

Petraglia, M., Korisettar, R., Boivin, N., Clarkson, C., Ditchfield, P., Jones, S., Koshy, J., Lahr, M.M., Oppenheimer, C., Pyle, D., Roberts, R., Schwenninger, J.-L., Arnold, L., White, K., 2007. Middle Paleolithic assemblages from the Indian subcontinent before and after the Toba super-eruption. Science 317, 114-116. 
Pitarch Martí, A., Wei, Y., Gao, X., Chen, F., d'Errico, F., 2017. The earliest evidence of coloured ornaments in China: The ochred ostrich eggshell beads from Shuidonggou Locality 2. J. Anthropol. Archaeol. 48, 102-113.

Pitulko, V.V., Pavlova, E.Y., Nikolskiy, P.A., Ivanova, V.V., 2012. The oldest art of the Eurasian Arctic: Personal ornaments and symbolic objects from Yana RHS, Arctic Siberia. Antiquity 86, 642-659.

Preston-Whyte, E., 1994. Speaking with Beads. Thames and Hudson, London.

Qi, Z., 2004. Seashells of China. China Press, Beijing.

Qu, T., Bar-Yosef, O., Wang, Y., Wu, X., 2013. The Chinese Upper Paleolithic: Geography, chronology, and techno-typology. J. Archaeol. Res. 21, 1-73.

Reynolds, T.E.G., 1991. Revolution or resolution? The archaeology of modern human origins. World Archaeol. 23, 155-166.

Rigaud, S., 2013. Les objets de parure associés au dépôt funéraire mésolithique de Große Ofnet: Implications pour la compréhension de l'organisation sociale des dernières sociétés de chasseurs-cueilleurs du Jura Souabe. Anthropozoologica 48, 207-230.

Rigaud, S., Vanhaeren, M., Queffelec, A., Le Bourdon, G., d'Errico, F., 2014. The way we wear makes the difference: Residue analysis applied to Mesolithic personal ornaments from Hohlenstein-Stadel (Germany). Archaeol. Anthropol. Sci. 6, 133-144.

Rigaud, S., d'Errico, F., Vanhaeren, M., 2015. Ornaments reveal resistance of North European cultures to the spread of farming. PLoS One 10, e0121166.

Rigaud, S., d'Errico, F., Vanhaeren, M., 2017. Les coquillages marins de Praileaitz I (Deba, Gipuzkoa). In: Peñalver, X., San Jose, S., Mujika-Alustiza, J.A. (Eds.), La Cueva de 
Praileaitz I (Deba, Gipuzkoa, Euskal Herria). Intervención Arqueológica 2000-2009.

Sociedad de Ciencias ARANZADI Zientzia Elkartea, Donostia, pp. 333-351.

Rigaud, S., Manen, C., Lagrán, I.G.-M. de, 2018. Symbols in motion: Flexible cultural boundaries and the fast spread of the Neolithic in the Western Mediterranean. PLoS One 13, e0196488.

Roebroeks, W., Sier, M.J., Nielsen, T.K., Loecker, D.D., Parés, J.M., Arps, C.E.S., Mücher, H.J., 2012. Use of red ochre by early Neandertals. Proc. Natl. Acad. Sci. USA 109, 18891894.

Rybin, E.P., 2015. Middle and Upper Paleolithic interactions and the emergence of "modern behavior" in Southern Siberia and Mongolia. In: Kaifu, Y., Izuho, M., Goebel, T., Sato, H., Ono, A. (Eds.), Emergence and Diversity of Modern Human Behavior in Paleolithic Asia. Texas A\&M University Press, College Station, Tx, pp. 470-489.

Sanders, J.M., 2002. Ethnic boundaries and identity in plural societies. Annu. Rev. Sociol. 28, $327-357$.

Shang, H., Tong, H., Zhang, S., Chen, F., Trinkaus, E., 2007. An early modern human from Tianyuan Cave, Zhoukoudian, China. Proc. Natl. Acad. Sci. USA 104, 6573-6578.

Sharp, L., 1934. Ritual life and economics of the Yir-Yoront of Cape York Peninsula. Oceania 5, $19-42$.

Shen, C., Zhang, X., Gao, X., 2016. Zhoukoudian in transition: Research history, lithic technologies, and transformation of Chinese Palaeolithic archaeology. Quat. Int. 400, 413.

Shen, G., Ku, T.-L., Cheng, H., Edwards, R.L., Yuan, Z., Wang, Q., 2001. High-precision Useries dating of Locality 1 at Zhoukoudian, China. J. Hum. Evol. 41, 679-688. 
Shen, G., Gao, X., Gao, B., Granger, D.E., 2009. Age of Zhoukoudian Homo erectus determined with ${ }^{26} \mathrm{Al} /{ }^{10} \mathrm{Be}$ burial dating. Nature 458, 198-200.

Shen, G., Wu, X., Wang, Q., Tu, H., Feng, Y., Zhao, J., 2013. Mass spectrometric U-series dating of Huanglong Cave in Hubei Province, Central China: Evidence for early presence of modern humans in Eastern Asia. J. Hum. Evol. 65, 162-167.

Shennan, S. (Ed.), 2009. Pattern and Process in Cultural Evolution, 1st ed. University of California Press, Berkeley.

Shidrang, S., 2018. The Middle to Upper Paleolithic transition in the Zagros: The appearance and evolution of the Baradostian. In: Nishiaki, Y., Akazawa, T. (Eds.), The Middle and Upper Paleolithic Archeology of the Levant and Beyond. Springer, Singapore, pp. 133-156.

Shunkov, M.V., Fedorchenko, A.Yu., Kozlikin, M.B., Derevianko, A.P., 2020. Initial Upper Palaeolithic ornaments and formal bone tools from the East Chamber of Denisova Cave in the Russian Altai. Quat. Int. 559, 47-67.

Sikora, M., Pitulko, V.V., Sousa, V.C., Allentoft, M.E., Vinner, L., Rasmussen, S., Margaryan, A., Damgaard, P. de B., Fuente, C. de la, Renaud, G., Yang, M.A., Fu, Q., Dupanloup, I., Giampoudakis, K., Nogués-Bravo, D., Rahbek, C., Kroonen, G., Peyrot, M., McColl, H., Vasilyev, S.V., Veselovskaya, E., Gerasimova, M., Pavlova, E.Y., Chasnyk, V.G., Nikolskiy, P.A., Gromov, A.V., Khartanovich, V.I., Moiseyev, V., Grebenyuk, P.S., Fedorchenko, A.Y., Lebedintsev, A.I., Slobodin, S.B., Malyarchuk, B.A., Martiniano, R., Meldgaard, M., Arppe, L., Palo, J.U., Sundell, T., Mannermaa, K., Putkonen, M., Alexandersen, V., Primeau, C., Baimukhanov, N., Malhi, R.S., Sjögren, K.-G., Kristiansen, K., Wessman, A., Sajantila, A., Lahr, M.M., Durbin, R., Nielsen, R., 
Meltzer, D.J., Excoffier, L., Willerslev, E., 2019. The population history of Northeastern Siberia since the Pleistocene. Nature 570, 182-188.

Sina News, 2005. Cavemen jewelry appeared in Zhoukoudian - 山顶洞人饰品现身周口店(组 图). Sina News. URL http://tech.sina.com.cn/d/2005-12-27/0818803240.shtml. Accessed 2021-02-09.

Song, Y., Shi, J., 2013. The stringing fashion of perforated ornaments at the Shizitan site (柿子 滩遗址穿孔饰品的穿系方式研究). Zongyuan wenwu (中原文物) 2013, 17-22.

Song, Y., Cohen, D.J., Shi, J., Wu, X., Kvavadze, E., Goldberg, P., Zhang, S., Zhang, Y., BarYosef, O., 2017. Environmental reconstruction and dating of Shizitan 29, Shanxi Province: An early microblade site in North China. J. Archaeol. Sci. 79, 19-35. Speck, F.G., 1940. Eskimo jacket ornaments of ivory suggesting function of bone pendants found in Beothuk sites in Newfoundland 345. Am. Antiq. 5, 225-228.

Steele, T.E., Álvarez-Fernández, E., Hallett-Desguez, E., 2019. A review of shells as personal ornamentation during the African Middle Stone Age. PaleoAnthropology 2019, 24-51.

Straffon, L.M., 2019. The uses of cultural phylogenetics in archaeology. In: Prentiss, A.M. (Ed.), Handbook of Evolutionary Research in Archaeology. Springer, Cham, pp. 149-160.

Stiner, M.C., Kuhn, S.L., Güleç, E., 2013. Early Upper Paleolithic shell beads at Üçağızlı Cave I (Turkey): Technology and the socioeconomic context of ornament life-histories. J. Hum. Evol. 64, 380-398.

Sun, X., Wen, S., Lu, C., Zhou, B., Curnoe, D., Lu, H., Li, Hong-chun, Wang, W., Cheng, H., Yi, S., Jia, X., Du, P., Xu, X., Lu, Yi-ming, Lu, Ying, Zheng, H., Zhang, H., Sun, C., Wei, L., Han, F., Huang, J., Edwards, R.L., Jin, L., Li, Hui, 2021. Ancient DNA and 
multimethod dating confirm the late arrival of anatomically modern humans in Southern China. Proc. Natl. Acad. Sci. USA 118, e2019158118.

Taylor, C.F., 1994. The Plain Indians. A Cultural and Historical View of the North American Plains Tribes of the Pre-Reservation Period. Salamander Books Limited, London.

Tong, H., Shang, H., Zhang, S., Chen, F., 2004. A preliminary report on the newly found Tianyuan Cave, a Late Pleistocene human fossil site near Zhoukoudian. Chi. Sci. Bull. 49, 853-857.

Trinkaus, E., Buzhilova, A.P., Diversity and differential disposal of the dead at Sunghir. Antiquity 92, 7-21.

Turner, T., 1980. The social skin. In: Cherfas, J., Lewin, R. (Eds.), Not Work Alone: CrossCultural Accounts of Activities Superfluous to Survival. Temple Smith, London, pp. $112-140$.

Vanhaeren, M., 2005. Speaking with beads: The evolutionary significance of personal ornaments. In: d'Errico, F., Backwell, L.R. (Eds.), From Tools to Symbols: From Early Hominids to Modern Humans. Wits University Press, Johannesburg, pp. 525-553.

Vanhaeren, M., d'Errico, F., 2001. La parure de l'enfant de la Madeleine (fouilles Peyrony). Un nouveau regard sur l'enfance au Paléolithique supérieur. PALEO 13, 201-240.

Vanhaeren, M., d'Errico, F., 2002. The body ornaments associated with the burial. In: Zilhão, J., Trinkaus, E. (Eds.), Portrait of the Artist as a Child. The Gravettian Human Skeleton from the Abrigo Do Lagar Velho and Its Archaeological Context. Instituto Português de Arqueologia, Lisboa, pp. 154-186. 
Vanhaeren, M., d'Errico, F., 2005. Grave goods from the Saint-Germain-la-Rivière burial:

Evidence for social inequality in the Upper Palaeolithic. J. Anthropol. Archaeol. 24, $117-$ 134.

Vanhaeren, M., d'Errico, F., 2006. Aurignacian ethno-linguistic geography of Europe revealed by personal ornaments. J. Archaeol. Sci. 33, 1105-1128.

Vanhaeren, M., d'Errico, F., 2017. Les incisives de bouquetin perforées de Praileaitz I (Deba, Gipuzkoa). Analyse archéozoologique et technologique. In: Peñalver, X., San Jose, S., Mujika-Alustiza, J.A. (Eds.), La Cueva de Praileaitz I (Deba, Gipuzkoa, Euskal Herria). Intervención Arqueológica 2000-2009. Sociedad de Ciencias ARANZADI Zientzia Elkartea, Donostia, pp. 485-492.

Vanhaeren, M., d'Errico, F., van Niekerk, K.L., Henshilwood, C.S., Erasmus, R.M., 2013. Thinking strings: Additional evidence for personal ornament use in the Middle Stone Age at Blombos Cave, South Africa. J. Hum. Evol. 64, 599-517.

Vanhaeren, M., Wadley, L., d'Errico, F., 2019. Variability in Middle Stone Age symbolic traditions: The marine shell beads from Sibudu Cave, South Africa. J. Archaeol. Sci. Rep. $27,101893$.

Vercoutère, C., 2003. Acquisition et traitement de l'animal en tant qu'ensemble de ressources non alimentaires: Les canines aménagées de renard de l'abri Pataud (Les-Eyzies-deTayac, Dordogne, France). In: Patou-Mathis, M., Cattelain, P., Ramseyer, D. (Eds.), L’Industrie Osseuse Pré- et Protohistorique en Europe: Approches Technologiques et Fonctionnelles. Cercle archéologique Hesbaye-Condroz, Amay, pp. 29-42. 
Watts, I., Chazan, M., Wilkins, J., 2016. Early evidence for brilliant ritualized display: Specularite used in the Northern Cape (South Africa) between 500 and 300 Ka. Curr. Anthropol. 57, 287-310.

Wei, Y., d'Errico, F., Vanhaeren, M., Li, F., Gao, X., 2016. An early instance of Upper Palaeolithic personal ornamentation from China: The freshwater shell bead from Shuidonggou 2. PLoS One 11, e0155847.

Wei, Y., d'Errico, F., Vanhaeren, M., Peng, F., Chen, F., Gao, X., 2017. A technological and morphological study of Late Paleolithic ostrich eggshell beads from Shuidonggou, North China. J. Archaeol. Sci. 85, 83-104.

Weidenreich, F., 1939. On the earliest representatives of modern mankind on the soil of East Asia. Peking Nat. Hist. Bull. 13, 161-179.

White, R., 2007. Systems of personal ornamentation in the Early Upper Palaeolithic: Methodological challenges and new observations. In: Mellars, P.A., Boyle, K., BarYosef, O., Stringer, C.B. (Eds.), Rethinking the Human Revolution. New Behavioural and Biological Perspectives on the Origin and Dispersal of Modern Humans. McDonald Institute for Archaeological Research, Cambridge, pp. 287-302.

WoRMS Editorial Board, 2021. World register of marine species. http://www.marinespecies.org at VLIZ. Accessed 2020-12-08.

Wright, D., Nejman, L., d’Errico, F., Králík, M., Wood, R., Ivanov, M., Hladilová, Š., 2014. An Early Upper Palaeolithic decorated bone tubular rod from Pod Hradem Cave, Czech Republic. Antiquity 88, 30-46.

Wu, X., 2004. On the origin of modern humans in China. Quat. Int. 117, 131-140. 
Xie, F., Li, J., Liu, L., 2006. The Paleolithic of the Nihewan Basin. Huashan Culture Press, Hebei.

Yang, M.A., Gao, X., Theunert, C., Tong, H., Aximu-Petri, A., Nickel, B., Slatkin, M., Meyer, M., Pääbo, S., Kelso, J., Fu, Q., 2017. 40,000-year-old individual from Asia provides insight into early population structure in Eurasia. Curr. Biol. 27, 3202-3208.e9.

Yue, J.-P., Yang, S.-X., Li, Y.-Q., Storozum, M., Hou, Y.-M., Chang, Y., Petraglia, M.D., 2021. Human adaptations during MIS 2: Evidence from microblade industries of Northeast China. Palaeogeogr. Palaeoclimatol. Palaeoecol. 567, 110286.

Zhang, J.F., Huang, W.W., Yuan, B.Y., Fu, R.Y., Zhou, L.P., 2010. Optically stimulated luminescence dating of cave deposits at the Xiaogushan prehistoric site, Northeastern China. J. Hum. Evol. 59, 514-524.

Zhang, S., Doyon, L., Zhang, Y., Gao, X., Chen, F.Y., Guan, Y., d’Errico, F., 2018. Innovation in bone technology and artefact types in the Late Upper Palaeolithic of China: Insights from Shuidonggou Locality 12. J. Archaeol. Sci. 93, 82-93.

ZK The Institute of Archaeology, Chinese Academy of Social Sciences, 1977. Radiocarbon dating report (4). Kaogu/Archaeology 3, 200-204.

ZK The Institute of Archaeology, Chinese Academy of Social Sciences, 1980. Radiocarbon dating report (7). Kaogu/Archaeology 4, 372-377.

\section{Figure Legends}


Figure 1. Schematic drawing of Zhoukoudian Upper Cave stratigraphy, modified after Pei (1939: Fig. 1). Top: location of the site in the Dragon Bone Hill of Zhoukoudian; Lower left: North-South profile; Lower right: East-West profile. Black lenses in the profiles correspond to cultural layers L1-L5. En = Entrance; $\mathrm{R}=$ Upper room; $\mathrm{r}=$ Lower room; $\mathrm{Lr}=$ Lower recess. Symbols in the stratigraphic profiles correspond to a) bone eyed needle, b and c) human skulls, and d) perforated marine shell.

Figure 2. Rediscovered badger teeth from Zhoukoudian Upper Cave curated at the Zhoukoudian Site Museum. Notice the abundant red residue present in and around the perforation on all three specimens, and the coarser greyish sediment adhering to the root of the complete specimen. See Table 2 for details. In Tables 4 and 5, the SEM-EDS and $\mu$-RS results from the analyses of the sediments and red residues are provided for teeth no. 1 (A), no. 2 (B) and no. 3 (C). Scale $=1 \mathrm{~cm}$.

Figure 3. Casts of Zhoukoudian Upper Cave objects interpreted by Pei as personal ornaments. The casts were produced in 1939 and are curated at the Institute of Vertebrate Paleontology and Paleoanthropology, Beijing. See Tables 2 and 3, and SOM Table S1 for details. Scale $=1 \mathrm{~cm}$.

Figure 4. Correspondence analysis of data on the location, size, morphology and technology of perforations on animal teeth used as personal ornaments at Zhoukoudian Upper Cave. Notice that radial incising is typically found in layer L2 and bidirectional incising in layer L4. Other perforation techniques are ubiquitous. Confidence ellipses at $90 \%$. 
Figure 5. Close-up views of the perforations and use-wear on the Zhoukoudian Upper Cave rediscovered badger teeth. Notice the large facet on the labial aspect of the teeth $(\mathrm{B}, \mathrm{D}, \mathrm{I})$. Black, vertical bars indicate the location of the areas enlarged in the micrographs on the right $(\mathrm{C}, \mathrm{F}, \mathrm{G}$, J). Scales (white, horizontal bars): macro views (A, B, D, E, H, I) $=5 \mathrm{~mm}$; microscopic views $(\mathrm{C}, \mathrm{F}, \mathrm{G}, \mathrm{J})=1 \mathrm{~mm}$.

Figure 6. Analyses conducted on sediment adhering to the root of rediscovered complete badger tooth and covering the red residues. A) Location of the sampled area; B) Micrograph of the sample; C) SEM image in BSE mode. The dotted square indicates the area enlarged in D; D) Close-up view with the location of the analyzed area and spot; E) EDS spectrum obtained from the analyzed area and spot. Notice the high content of $\mathrm{Si}, \mathrm{Al}, \mathrm{Mg}, \mathrm{Ti}, \mathrm{Fe}$ indicating the presence of aluminosilicate crystals and rare iron/titanium rich oxy-hydroxide crystals (SP 1). See Table 4 for identification of major and minor elements.

Figure 7. Analyses conducted on the red residue adhering to the rediscovered complete badger tooth (see Fig. 2). A) Location of the sampled area; B) Microphotograph of the red residue; C-F) SEM images in BSE mode at different magnifications. Dotted areas in C and D are enlarged in D-F. Circles indicate the location of the analyzed spots. Notice sub-angular crystals, identified as iron/manganese-rich oxy-hydroxides and feldspars, platy-like particles, probably aluminosilicates, and small angular crystals mixed with tiny platelets. See Table 4 for identification of major and minor elements. 
Figure 8. Selected Raman spectra and microscopic views of the analyzed areas on red residues adhering to the Zhoukoudian Upper Cave rediscovered badger teeth. A) Complete specimen illustrated in Fig. 2A; B) Broken specimen illustrated in Fig. 2B; C) Broken specimen illustrated in Fig. 2C. $\mathrm{C}=$ calcite; $\mathrm{H}=$ hæmatite; $\mathrm{Ms}=$ muscovite; $\mathrm{Mc}=$ microcline; $\mathrm{Q}=$ quartz. All three spectra identify hæmatite. Microcline is detected in A and Muscovite in B. Dots indicate unresolved RS bands. See Table 5 for details. Scales $=50 \mu \mathrm{m}$.

Figure 9. Analyses conducted on the red residues adhering to one of the broken badger teeth (see Fig. 2B). A) Location of the sampled area; B) Microphotograph of the red residues. Squares indicate particles analyzed in the present study; C-F) SEM images in BSE mode at different magnifications. Dotted area in D is enlarged in E. Circles indicate the analyzed spots. Notice the presence of micrometric sub-angular crystals of iron oxy-hydroxides with variable proportions of manganese in association with platelets of clay minerals micrometric, sub-angular carbonate crystals and rounded silicate crystals. See Table 4 for identification of major and minor elements.

Figure 10. Analyses conducted on the red residues adhering to the second broken badger tooth (see Fig. 2C). A) Location of the sampled area; B) Microphotograph of the red residues; C-E) SEM images in BSE mode at different magnifications. Dotted areas in C are enlarged in D-E. Circles indicate the analyzed spots. Notice the presence of sub-angular crystals coated with a mix of platy-like and sub-angular crystals, mostly composed of Fe, Mn. See Table 4 for identification of major and minor elements. 
Figure 11. Photographs of two fossilized teeth exhibited at the Zhoukoudian Site Museum, interpreted in the current study as fakes. See Tables 2 and 3 for details. Scale $=1 \mathrm{~cm}$.

Figure 12. Close-up view of the recent perforations present on the two fossilized teeth exhibited in the Zhoukoudian Site Museum. Labial (B, D) and lingual (A, C) aspects of the felid (A, B) and red deer $(C, D)$ canines. Notice the fringed outlines, freshness, small diameter, funnel-like morphology of the perforations and absence of patina and sediment. Scales $=1 \mathrm{~mm}$.

Figure 13. Location of the sites included in the seriation (top). Seriation of the ornament types found in the archaeological layers of Late Paleolithic Northern Chinese sites dated between 40 and $10 \mathrm{ka}$ (bottom). Numbers in brackets following the site name and layer refer to the numbers on the map. The seriation identifies a difference in preferred ornament types between sites roughly located east and west of the $112^{\circ} \mathrm{E}$ longitude, and a chronological continuity encompassing the period between 40 and $10 \mathrm{ka}$ in the West, and a shorter timespan (40 to $25 \mathrm{ka}$ ) in the East. Map made by LD using QGIS v. 2.14.3-Essen (Free Software Foundation, Inc., Boston) and free vector and raster from Natural Earth (naturalearthdata.com).

Figure 14. Schematic rendition of how the complete badger tooth might have been attached to the clothing of Zhoukoudian Upper Cave visitors based on the location of a large ground facet on the labial aspect and shallow notches produced by use-wear on either side of the perforation on the lingual aspect. 


\section{Table 1}

Stratigraphic provenience and numbers of Zhoukoudian Upper Cave personal ornaments as reported by Pei (1939).

\begin{tabular}{|c|c|c|c|c|c|c|c|c|c|}
\hline \multirow{2}{*}{$\begin{array}{c}\text { Pei's } \\
\text { cultural } \\
\text { layers }\end{array}$} & \multirow{2}{*}{ Hæmatite } & \multirow{2}{*}{$\begin{array}{l}\text { Stone } \\
\text { beads }\end{array}$} & \multirow{2}{*}{$\begin{array}{l}\text { Perforated } \\
\text { pebble }\end{array}$} & \multicolumn{2}{|c|}{ Perforated teeth } & \multirow[t]{2}{*}{ Bone tube } & \multirow[t]{2}{*}{$\begin{array}{c}\text { Perforated } \\
\text { shell }\end{array}$} & \multirow[t]{2}{*}{$\begin{array}{l}\text { Perforated } \\
\text { fish bone }\end{array}$} & \multirow[t]{2}{*}{ Total } \\
\hline & & & & Carnivore & Herbivore & & & & \\
\hline L1 & Present & & & & & & & & \\
\hline L2 & Present & & & $\begin{array}{c}n=28 \\
\text { collected } \\
\text { over an } \\
\text { area not } \\
\text { exceeding } 1 \\
\text { square } \\
\text { meter }\end{array}$ & & $n=1$ & & & 29 \\
\hline L3 & Present & & & & & & & & \\
\hline $\begin{array}{l}\text { Sediments } \\
\text { between L3 } \\
\text { and L4 }\end{array}$ & $\begin{array}{l}\text { Particles in } \\
\text { the matrix } \\
\text { adhering to } \\
\text { UC101, } \\
\text { UC102, } \\
\text { UC103 } \\
\text { skulls }\end{array}$ & $\begin{array}{l}\quad n=7 \\
\text { adhering to } \\
\text { UC102 skull }\end{array}$ & & & $\begin{array}{l}n=1 \text { deer } \\
\text { canine } \\
\text { found near } \\
\text { UC102 skull }\end{array}$ & & & & 8 \\
\hline L4 & Present & & $n=1$ & $\begin{array}{c}\text { Mostly } \\
\text { found in L4 } \\
(n \approx 80)^{\mathrm{a}}\end{array}$ & $\begin{array}{c}\text { Mostly } \\
\text { found in L4 } \\
(n \approx 16)^{b}\end{array}$ & $\begin{array}{l}\text { Probable }^{c} \\
\qquad(n \approx 3)\end{array}$ & $n=3$ & & $\approx 103$ \\
\hline L5 & Present & & & & & & & & \\
\hline Unknown & & & & & & & & 1 & 1 \\
\hline Total & & 7 & 1 & 108 & 17 & 4 & 3 & 1 & 141 \\
\hline
\end{tabular}

${ }^{a}$ Pei only indicates the cultural layer for the 28 carnivore canines recovered in a single square meter of L2. The other specimens are assumed to come from L4.

${ }^{b}$ Pei only indicates that one red deer canine was found closed to UC102. There are no indications that perforated deer canines were found in L2. Therefore, the other specimens are assumed to come from L4.

${ }^{c}$ Based on Pei's (1939:31) statement that "One (tubular bone pendant) was found in L2 in situ and the others $(n=3)$ from the sieved material for which the exact level could not be located. But judging by their appearance, they might have come from L4." 


\section{Table 2}

Descriptive and morphometric data on the Zhoukoudian Upper Cave personal ornaments-casts (Nos. 1-14), rediscovered (Nos. 15-17), and fake (No. 18)-analyzed in the present study. See Table 3 for data on perforated red deer canines.

\begin{tabular}{|c|c|c|c|c|c|c|c|c|c|c|c|c|}
\hline \multirow[b]{3}{*}{$\mathbf{N}^{\circ}$} & \multirow[b]{3}{*}{ Institution } & \multirow[b]{3}{*}{ Figure } & \multirow[b]{3}{*}{$\begin{array}{c}\text { Raw } \\
\text { material }\end{array}$} & \multirow[b]{3}{*}{ Species } & \multirow[b]{3}{*}{$\begin{array}{l}\text { Anatomical } \\
\text { position/ } \\
\text { side }\end{array}$} & \multicolumn{7}{|c|}{ Morphometric variables (mm) } \\
\hline & & & & & & \multicolumn{5}{|c|}{ All specimens } & \multicolumn{2}{|c|}{ Teeth only } \\
\hline & & & & & & Length ${ }^{a, b}$ & Width c,d & Thickness ${ }^{d}$ & $\begin{array}{l}\text { Perforation } \\
\text { maximum } \\
\text { diameter }\end{array}$ & $\begin{array}{l}\text { Perforation } \\
\text { minimum } \\
\text { diameter }\end{array}$ & $\begin{array}{l}\text { Crown } \\
\text { length }\end{array}$ & $\begin{array}{l}\text { Root } \\
\text { length }\end{array}$ \\
\hline 1 & IVPP & $3 \mathrm{~A}$ & Shell & Anadara disparilis/satowi & & 33.57 & 38.59 & 14.76 & 10.54 & 10.56 & & \\
\hline 2 & IVPP & 3В & Shell & Anadara broughtonii & & 30.92 & 35.44 & 13.72 & 8.8 & 8.38 & & \\
\hline 3 & IVPP & $3 C$ & Shell & Anadara broughtonii & & 23.49 & 30.16 & 10.8 & 4.75 & 3.69 & & \\
\hline 4 & IVPP & $3 D$ & Pebble & & & 40.08 & 28.76 & 12.05 & 3.28 & 2.63 & & \\
\hline 5 & IVPP & $3 \mathrm{E}$ & Calcite & & & 7.37 & 7.59 & 2.5 & 2.68 & 2.22 & & \\
\hline 6 & IVPP & $3 \mathrm{~F}$ & Calcite & & & 7.33 & 7.15 & 2.38 & 2.24 & 2.38 & & \\
\hline 7 & IVPP & $3 \mathrm{G}$ & Bone & Aves & & 39.16 & 13.15 & 9.86 & Inc. & Inc. & & \\
\hline 8 & IVPP & $3 \mathrm{H}$ & Bone & Aves & & 31.4 & 14.38 & 11.93 & Inc. & Inc. & & \\
\hline 9 & IVPP & 31 & Bone & Aves & & 18.72 & 14.48 & 12.02 & Inc. & Inc. & & \\
\hline 10 & IVPP & 3ง & Bone & Ctenopharyngodon idella & & 24.56 & 14.44 & 5.89 & 1.57 & 11.54 & & \\
\hline 11 & IVPP & $3 \mathrm{~K}$ & Tooth & Meles sp. & Lower/right & 27.84 & 9.31 & 7.06 & 2.07 & 1.86 & 14.82 & 14.92 \\
\hline 12 & IVPP & $3 \mathrm{~L}$ & Tooth & Vulpes sp. & Upper/right & 32.43 & 7.55 & 5.36 & 2.28 & 1.89 & 15.98 & 15.89 \\
\hline 13 & IVPP & $3 \mathrm{M}$ & Tooth & Vulpes sp. & Lower/right & 30.4 & 6.98 & 4.76 & 2.14 & 1.98 & 16.03 & 13.1 \\
\hline 14 & IVPP & $3 N$ & Tooth & Vulpes sp. & Lower/right & 28.53 & 6.3 & 5.18 & 1.33 & 1.33 & 14.4 & 14.67 \\
\hline 15 & ZKD & $2 \mathrm{~A}$ & Tooth & Meles sp. & Lower/left & 26.12 & 7.67 & 5.53 & 2.35 & 2.02 & 11.41 & 17.08 \\
\hline 16 & ZKD & $2 \mathrm{~B}$ & Tooth & Meles sp. & Lower/right & 22.4 & 7.5 & 5.33 & Inc. & 2.1 & 10.98 & Inc. \\
\hline 17 & ZKD & $2 C$ & Tooth & Meles sp. & Lower/left & Inc. & 5.98 & 4.84 & Inc. & 1.6 & Inc. & Inc. \\
\hline 18 & ZKD & $11 \mathrm{~A}$ & Tooth & Felix sp. & & 22.64 & 8.68 & 4.54 & 0.84 & 0.84 & & \\
\hline
\end{tabular}

Abbreviations: IVPP = Institute of Vertebrate Paleontology and Paleoanthropology; ZKD = Zhoukoudian Site Museum; Inc. = incomplete and therefore not measured.

${ }^{a}$ Maximum diameter for calcite beads.

${ }^{\mathrm{b}}$ Height of Arca sp. shells.

${ }^{\mathrm{c}}$ Minimum diameter for calcite beads.

${ }^{\mathrm{d}}$ Measured at the collar for Vulpes sp. and Meles sp. teeth. 


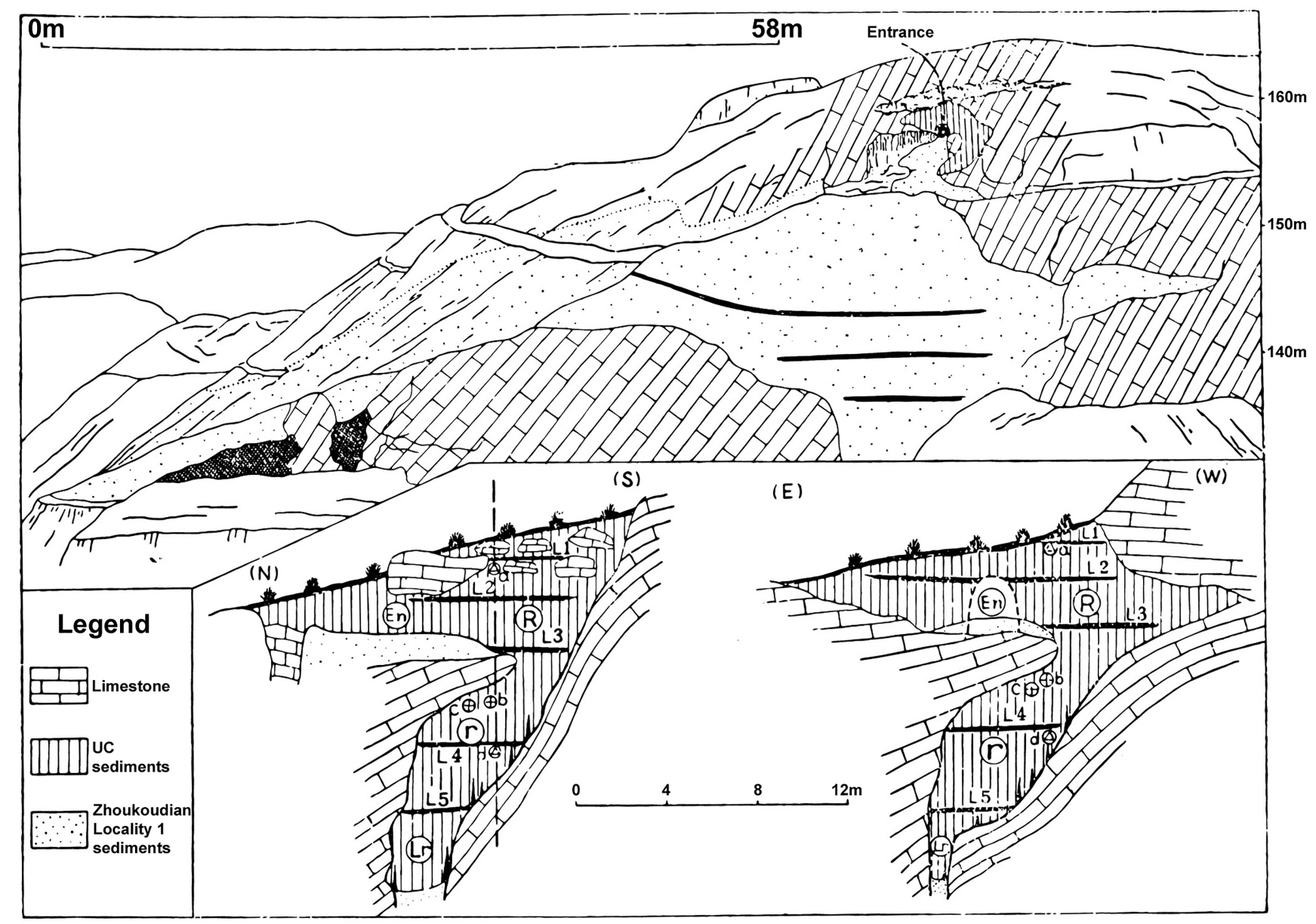



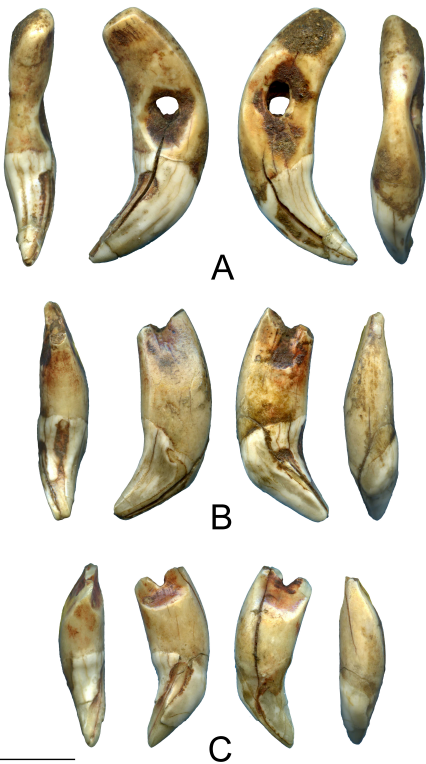
Axis 1: 0.198 (32.1\%)

Axis 2: 0.149 (25.4\%)

incision

$0,4-$
$0,0-$
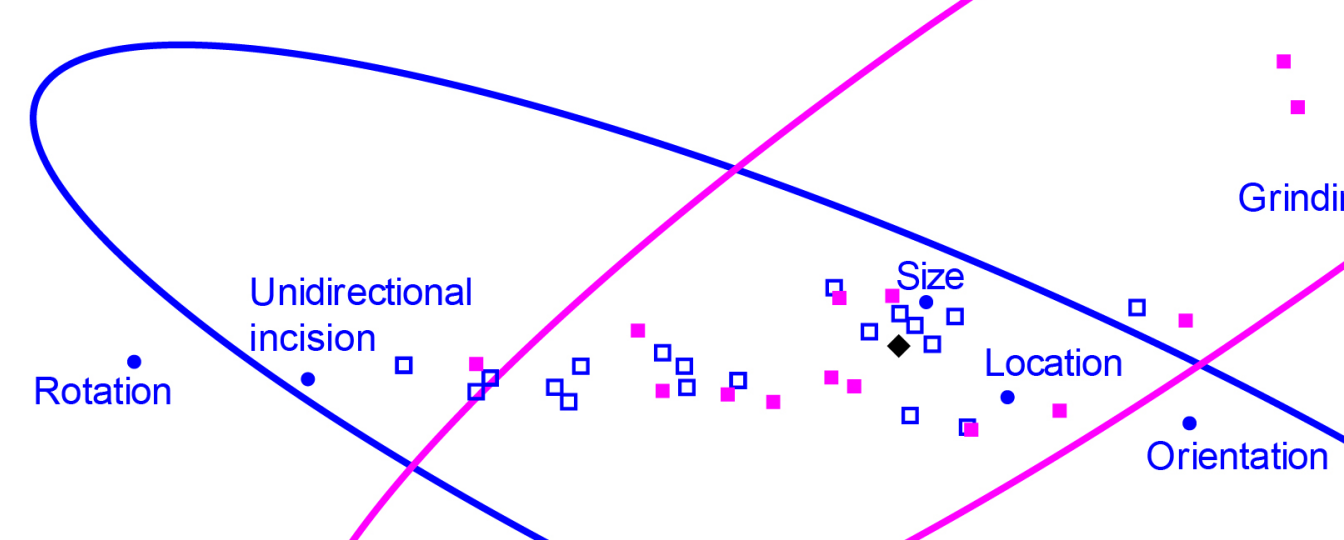

- Level 2

- Level 4

- Rediscovered tooth 


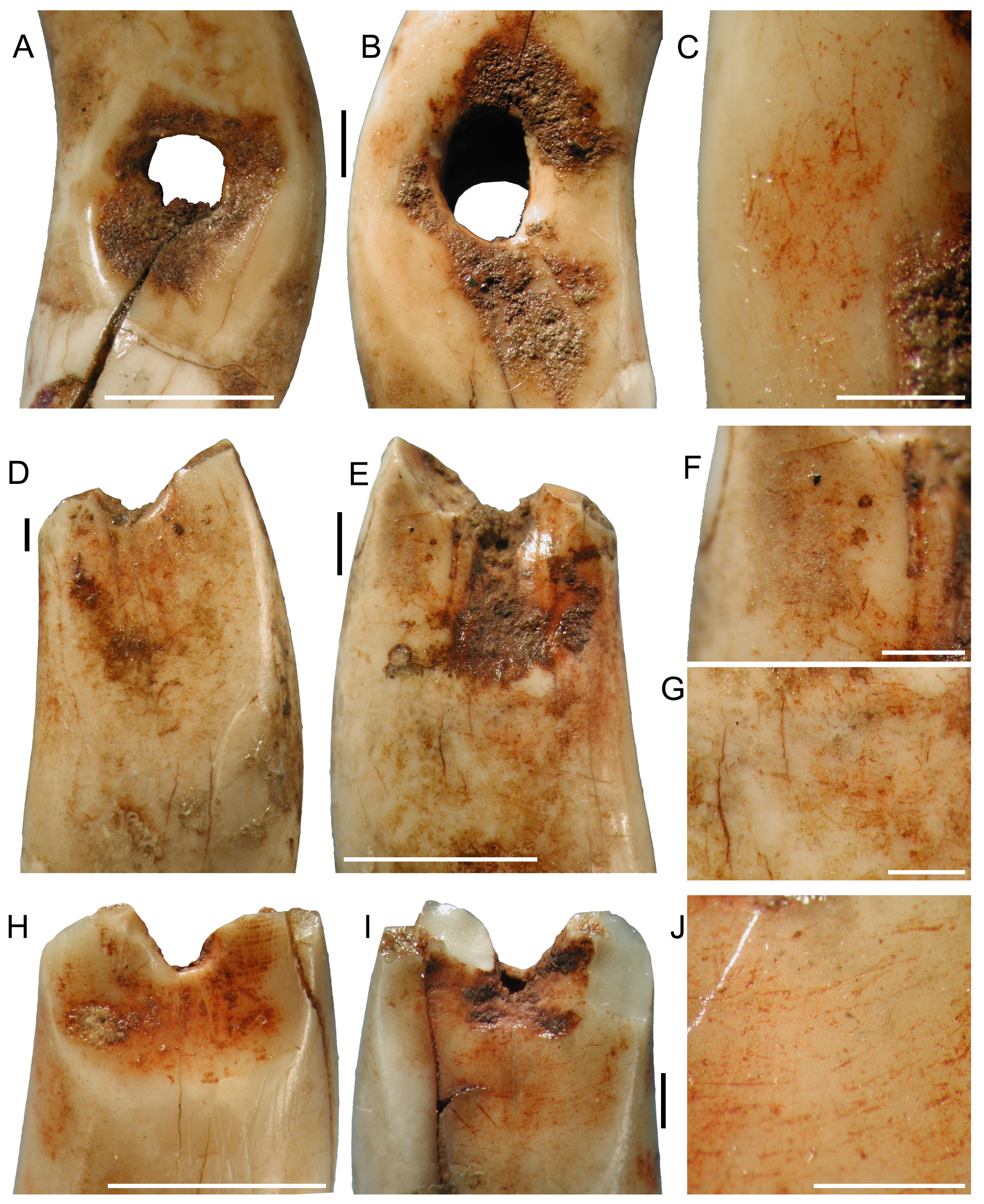



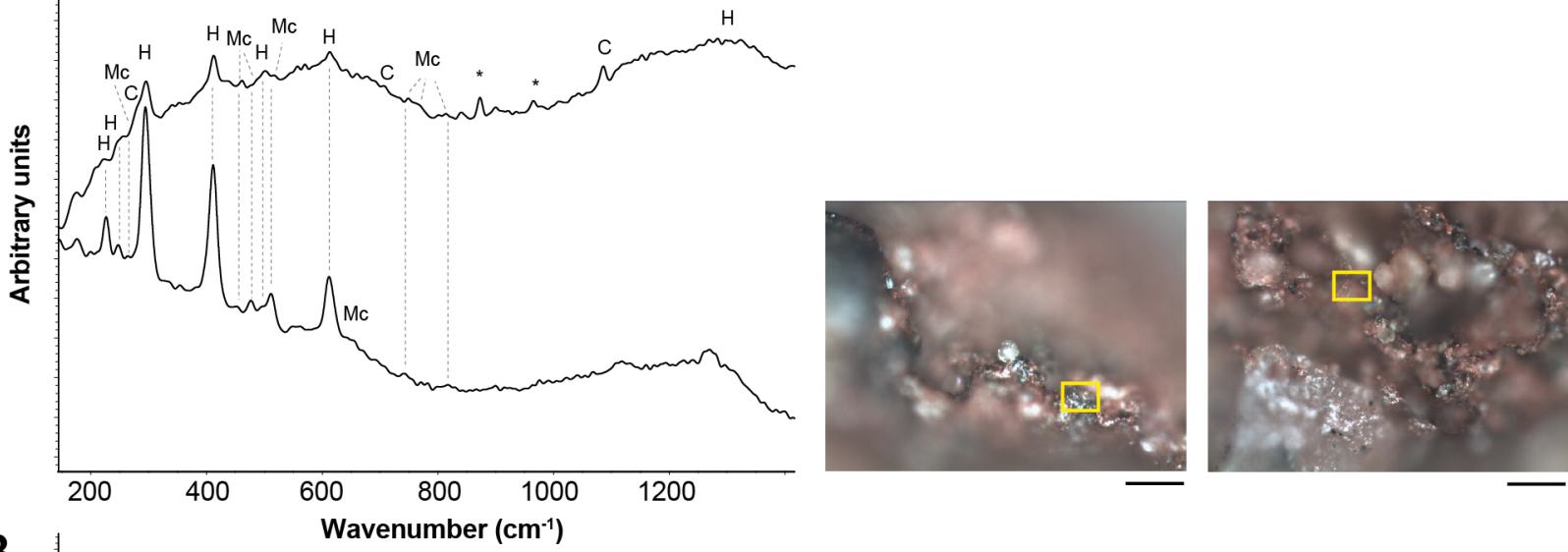

B
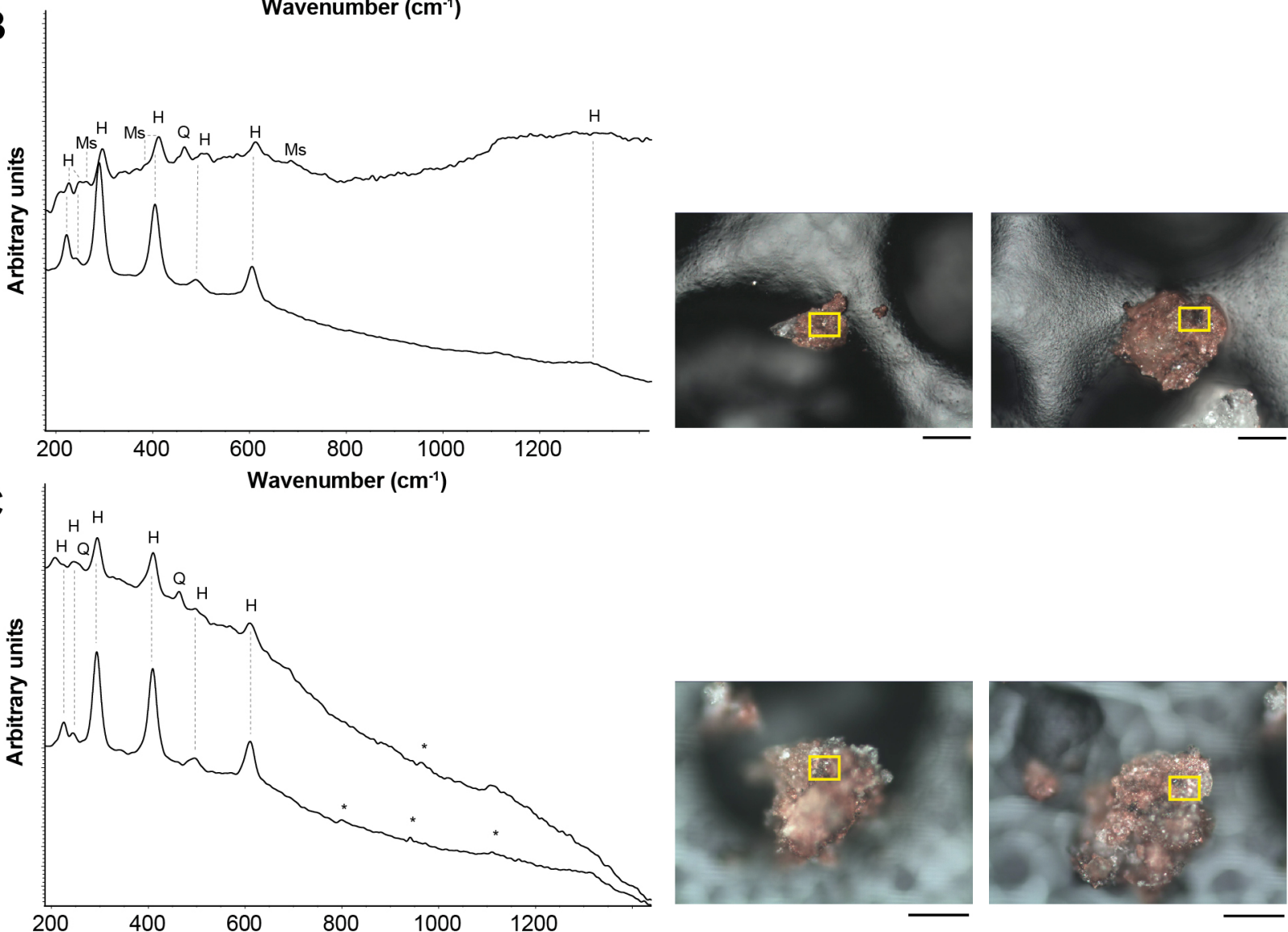

Wavenumber $\left(\mathrm{cm}^{-1}\right)$ 

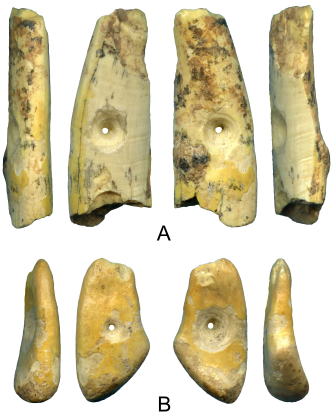


\section{$A=-\frac{10}{4}=10$}

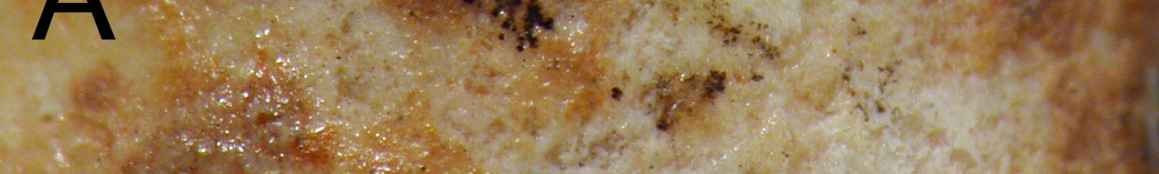

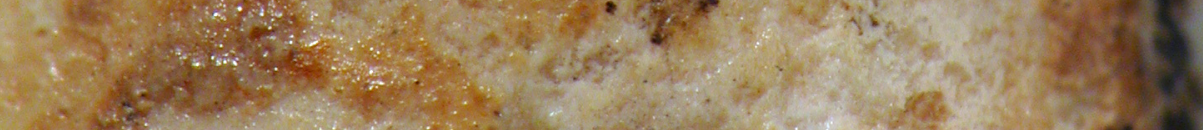
(c) 7. $x \rightarrow x^{2}$
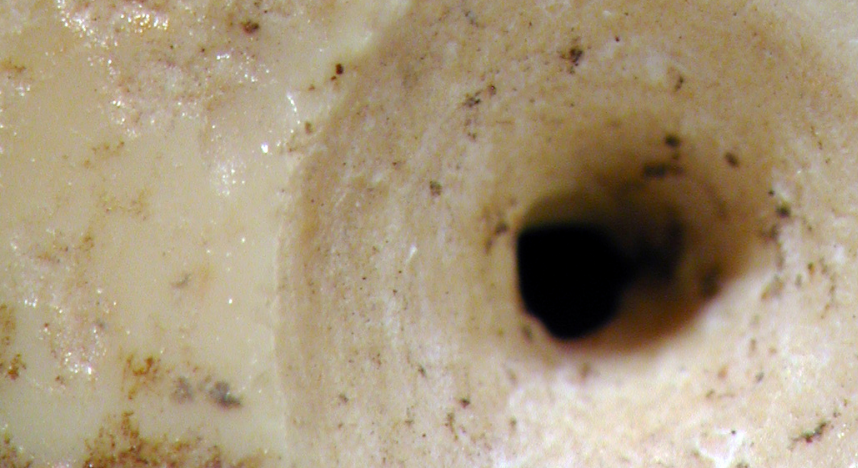

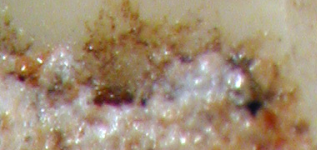
$9 y^{2}, y^{2}$

is.

○

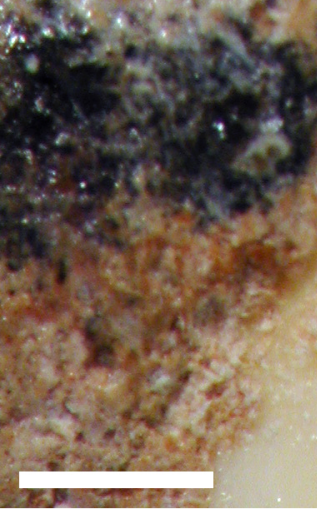

(1)

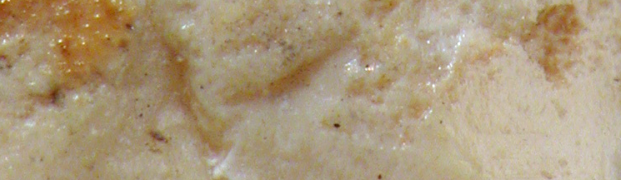

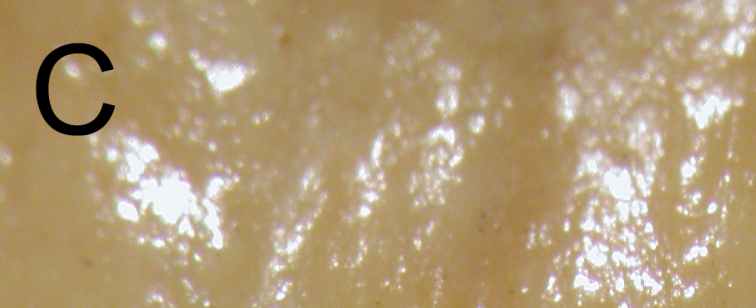 $\therefore \therefore \quad \cdots+1000$ $\left.\therefore x^{*}+2\right)+4$}

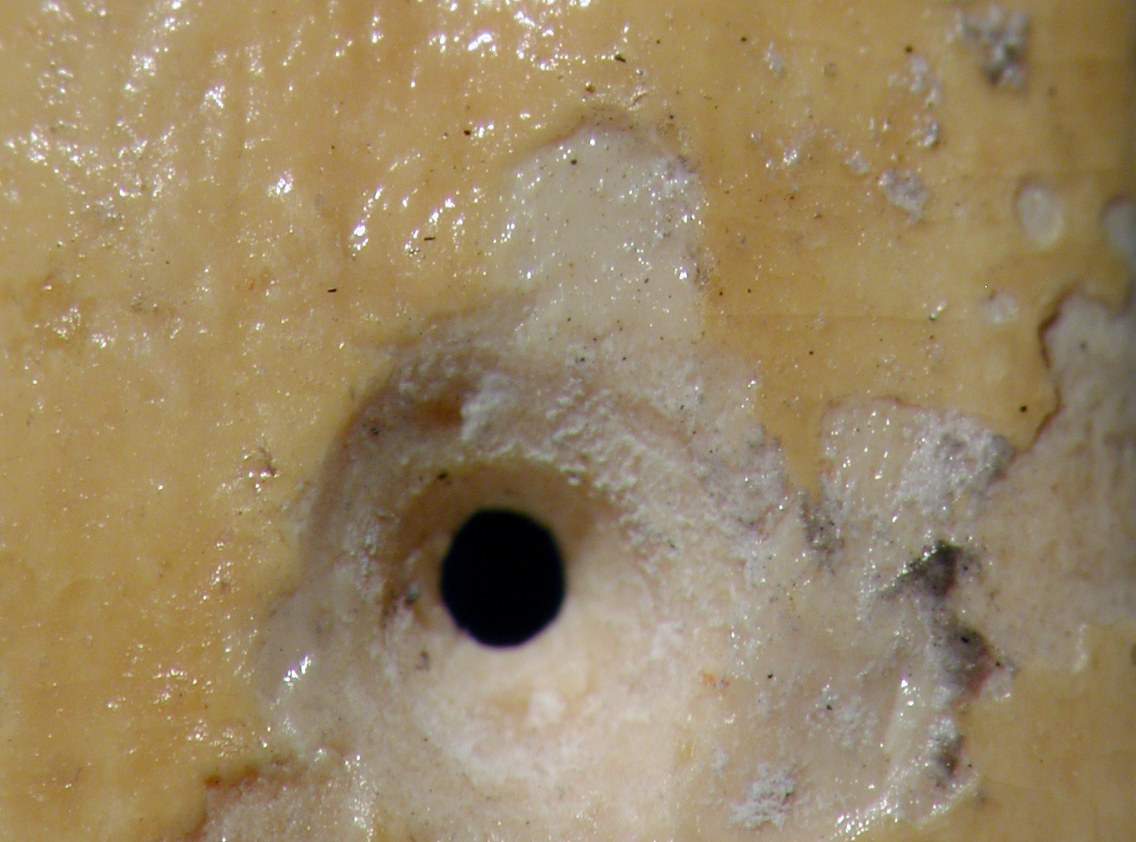

\section{$x^{2}+\operatorname{lom}^{4}$}

$$
+2
$$
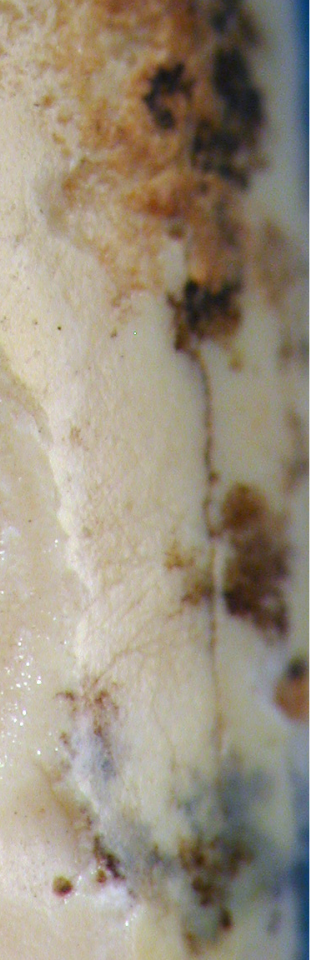
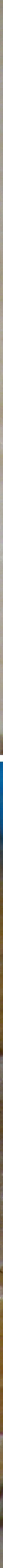


$$
f \rightarrow g
$$




\section{Supplementary Online Material (SOM):}

Zhoukoudian Upper Cave personal ornaments and ochre: Rediscovery and reevaluation

Francesco d'Errico ${ }^{\mathrm{a}, \mathrm{b},{ }^{*},}$, Africa Pitarch Martía,c, Yi Weid,e ${ }^{\mathrm{d}}$, Xing Gao ${ }^{\mathrm{d}, \mathrm{f}}$, Marian Vanhaeren ${ }^{\mathrm{a}}$, Luc Doyon ${ }^{\mathrm{a}, \mathrm{g}}$

a CNRS UMR5199 PACEA, Université de Bordeaux, Pessac CEDEX, France

b SFF Centre for Early Sapiens Behaviour (SapienCE), University of Bergen, Bergen, Norway

c Seminari d'Estudis i Recerques Prehistòriques (SERP), Departament d'Història i Arqueologia, Facultat de Geografia i Història, Universitat de Barcelona, Barcelona, Spain

d Centre for Excellence in Life and Paleoenvironment (CAS), Institute of Vertebrate Paleontology and Paleoanthropology, Chinese Academy of Sciences, Beijing, China

e Department of Scientific Research, Beijing Museum of Natural History, Beijing, China

f University of Chinese Academy of Sciences, Beijing, China

9 Institute of Cultural Heritage, Shandong University, Qingdao, China

\section{${ }^{*}$ Corresponding author.}

Email: francesco.derrico@u-bordeaux.fr (F.d'Errico) 
SOM Text S1. Quantitative method for the age estimation of red deer canines.

The quantitative method for the age estimation of red deer canines involves the use of two regression equations, one for stags and the other for hinds. The method described by d'Errico and Vanhaeren (2002) is summarized here.

To establish which equation should be used, the sex of the animal must first be established. This is done based on the tooth's morphology and the root width/thickness ratio. Young stag canines have a globular shape that tends, due to use-wear, to become triangular in older animals. Crowns of young hinds are pointed and become rectangular in old animals. In addition to these morphological characteristics, the root width is always more than twice its thickness among stags and less so among hind.

When the sex of the individual is determined, the corresponding regression equation may be used to estimate the age of the individual. For stags (Equation 1), the regression equation considers the lengths (-L) and widths (-W) of the crown (C-), root (R-) and wear facet (W-). The result is expressed in months.

$y=300.13+(-16.80 \mathrm{CL})+(9.28 \mathrm{WL})+(-6.69 \mathrm{RL})+(-12.74 \mathrm{CW})+(7.64 \mathrm{RW})+(-3.93 \mathrm{WW})$

Equation 1. Regression equation for the age estimation of red deer male individuals using the crown length $(\mathrm{CL})$, crown width (CW), root length (RL), root width (RW), wear facet length (WL) and wear facet width (WW).

For hind (Equation 2), the regression equation considers the crown length (CL), width (CW) and thickness (CT) as well as the wear facet length (WL) and width (WW). The result is expressed in months.

$$
y=222.09+(-10.83 \mathrm{CL})+\left(\frac{5.14(\mathrm{WL} * \mathrm{WW})}{2}\right)+\left(\frac{-5.75(\mathrm{CW} * \mathrm{CT})}{2}\right)
$$

Equation 2. Regression equation for the age estimation of red deer female individuals using the crown length $(\mathrm{CL})$, width $(\mathrm{CW})$ and thickness $(\mathrm{CT})$ as well as the wear facet length (WL) and width (WW). 

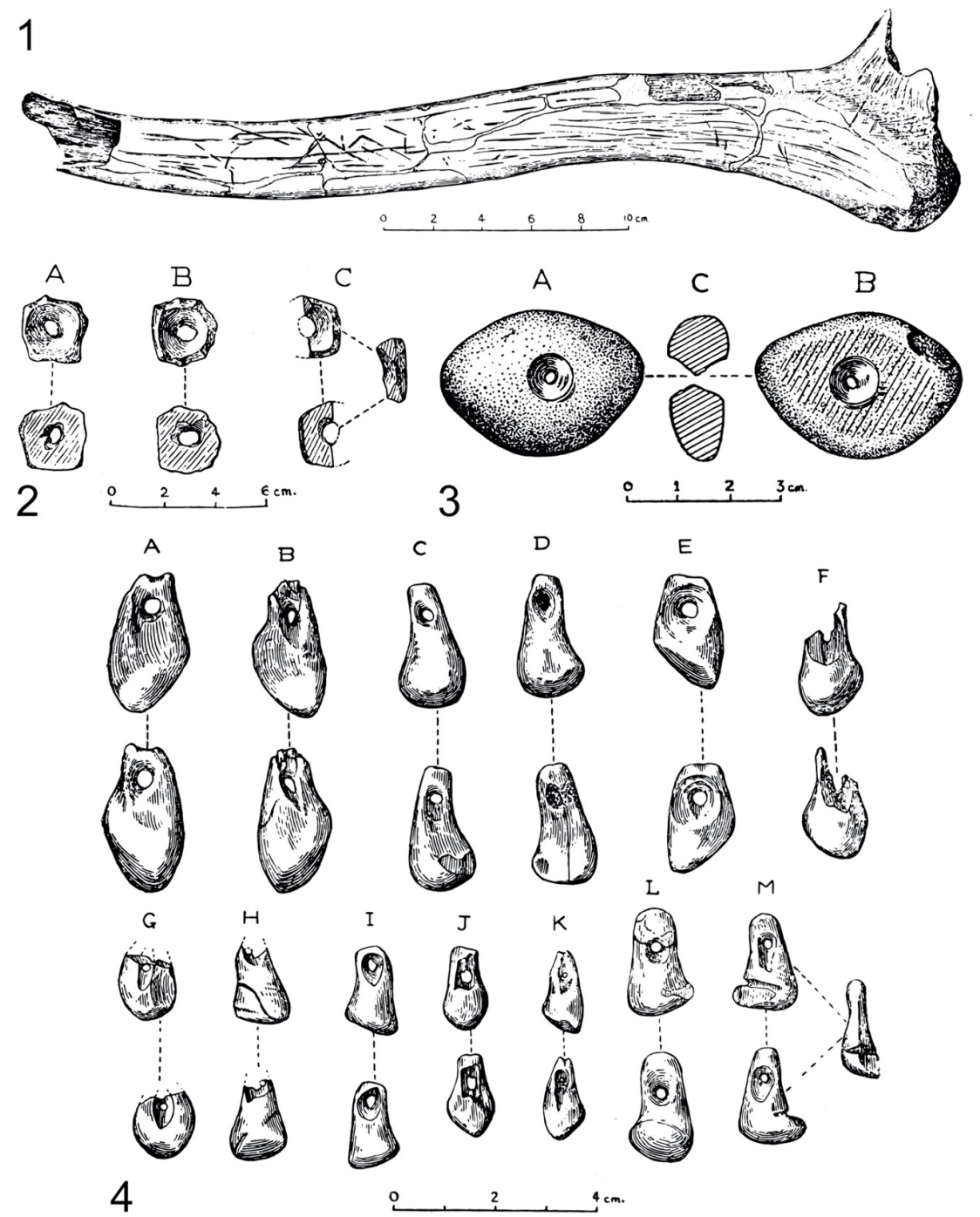

SOM Figure S1. Reproductions from Pei's (1939) monograph of Figure 10 showing a cervid antler bearing engraved incisions (1), Figure 11 showing perforated stone beads (2), Figure 12 showing a perforated pebble (3), and Figure 13-I depicting the perforated red deer canines (4). Scale in (2) is inaccurate in the original document; it should be $3 \mathrm{~cm}$ instead of $6 \mathrm{~cm}$. 

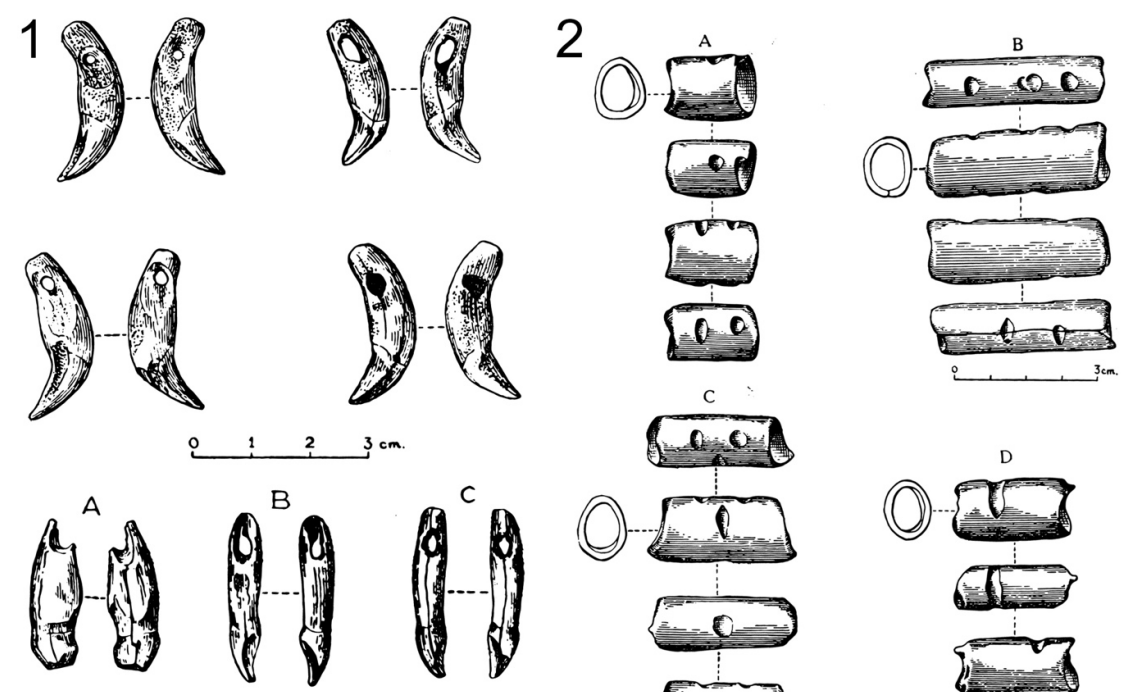

(C)
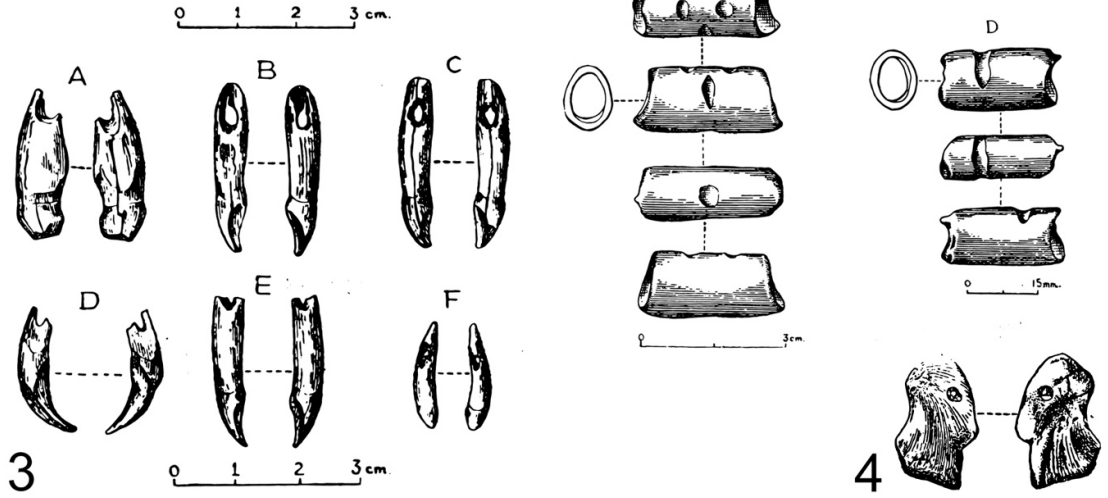

SOM Figure S2. Reproductions from Pei's (1939) monograph of Figure 13-II showing perforated badger canines (1), Figure 14 depicting four bone tubes with shallow notches (2), Figure 13-III showing (A) a tiger incisor, (B, C, E,) three Sika deer incisors, (D) a marten canine and (F) a red deer decidual canine (3), and Figure 15 a perforated grass carp supraorbital bone (4). Scale for (4) is absent in the original document. 


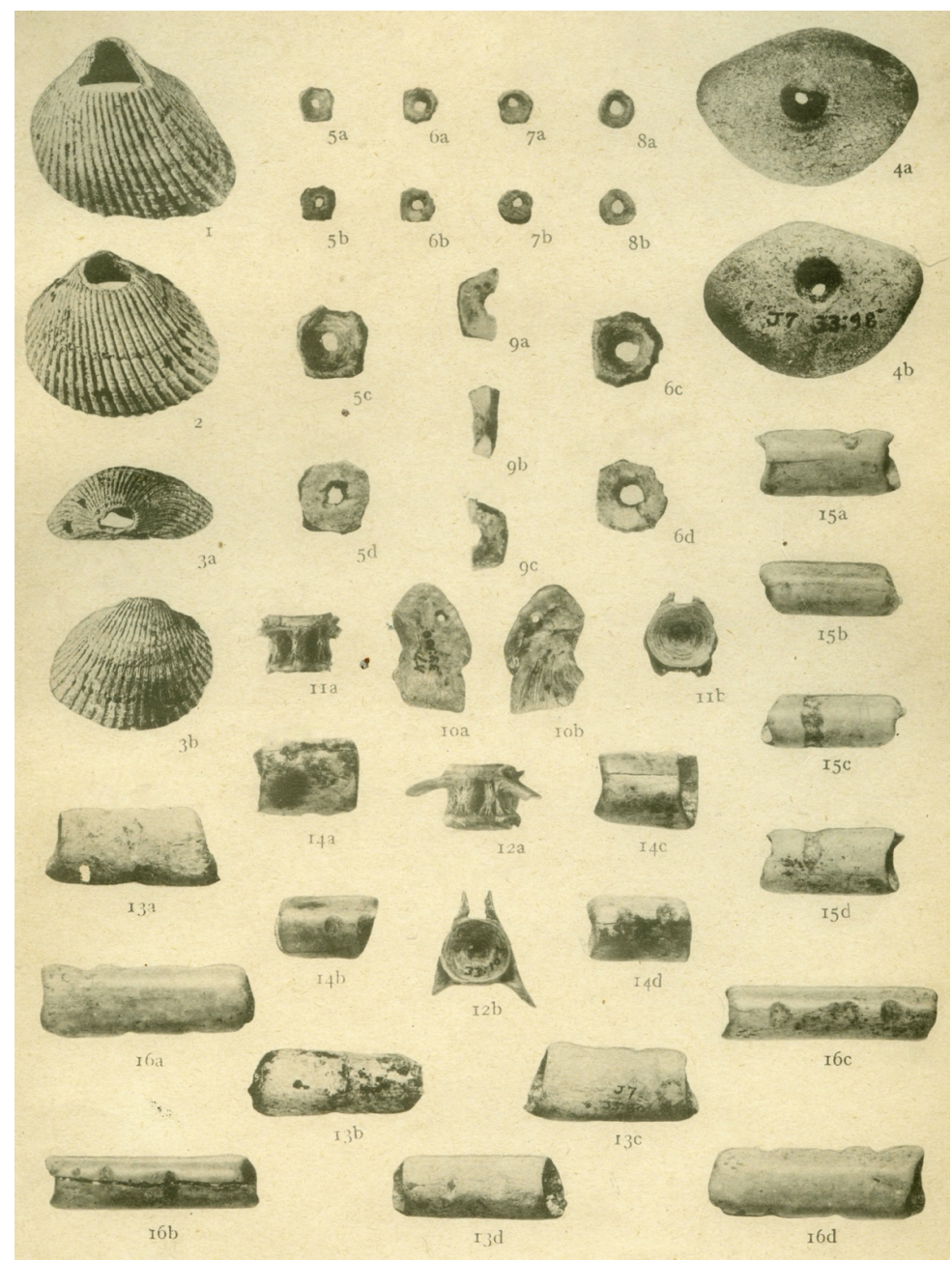

SOM Figure S3. Reproduction of Plate IV from Pei's (1939) monograph. Photographs of different aspects of perforated shells (1-3), pebble (4), stone beads (5-9), grass carp supraorbital bone (10) and bone tubes with shallow notches (13-16) are presented here. Note that the fish vertebrae (11-12) are not perforated and are not personal ornaments. 


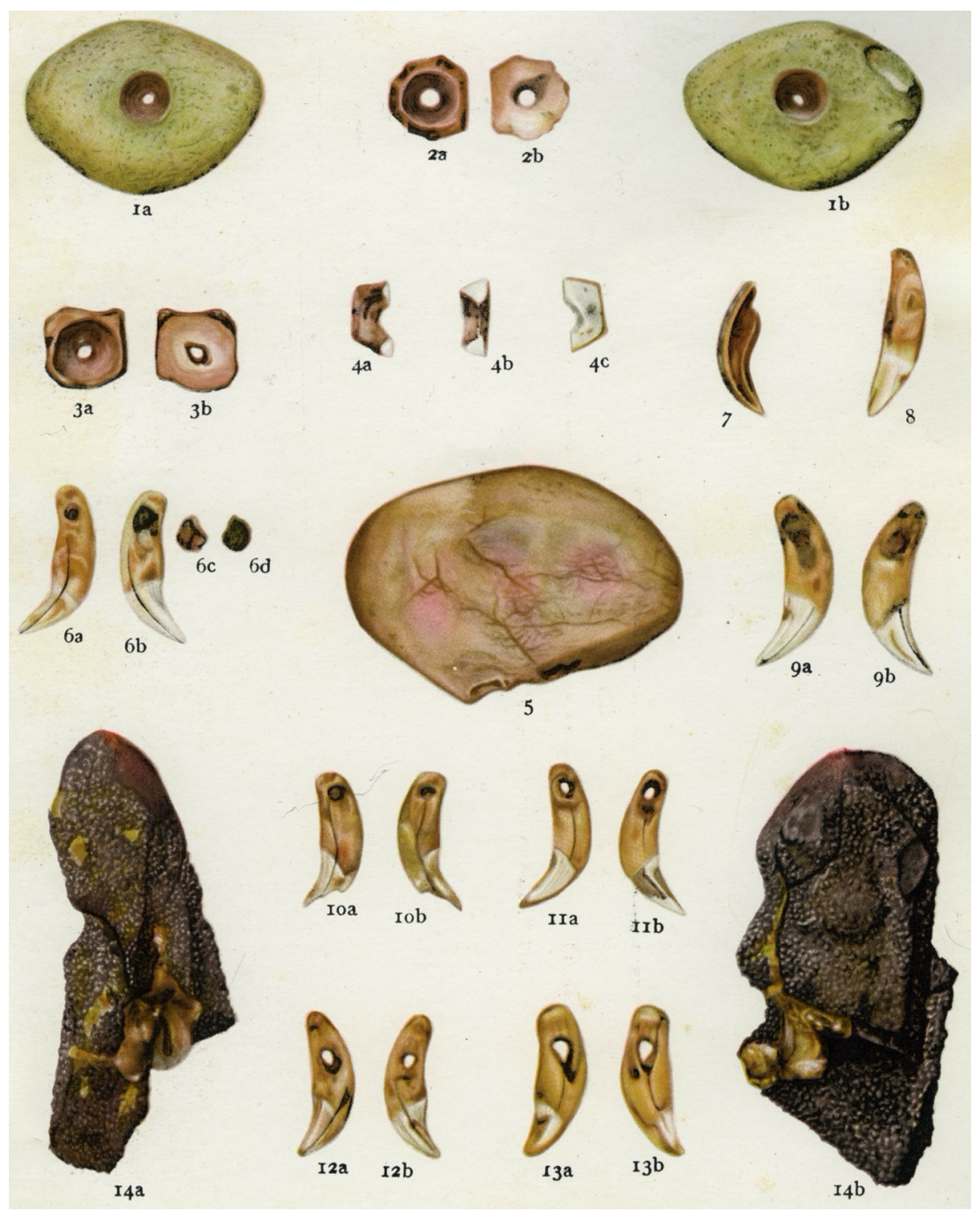

SOM Figure S4. Reproduction of Plate V from Pei's (1939) monograph. Watercolors of the perforated pebble (1), stone beads (2-4), perforated badger canines (6-13), a pebble with three red stains on one aspect (5) and a large piece of ochre (14). 


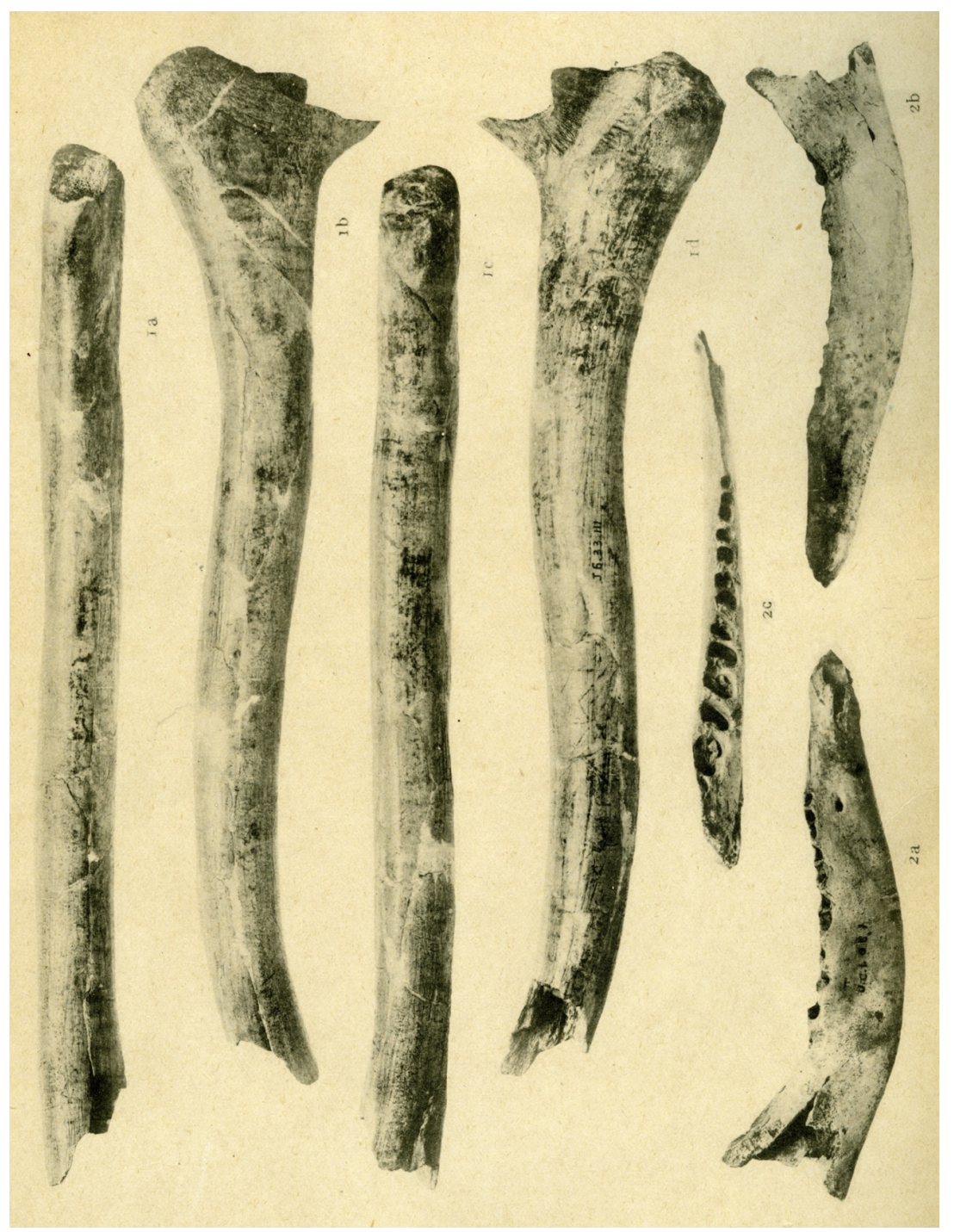

SOM Figure S5. Reproduction of Plate VI from Pei's (1939) monograph. Photographs of different aspects of the incised cervid antler (1) and the lower mandible of a Sika deer with an unusual polish (2). 


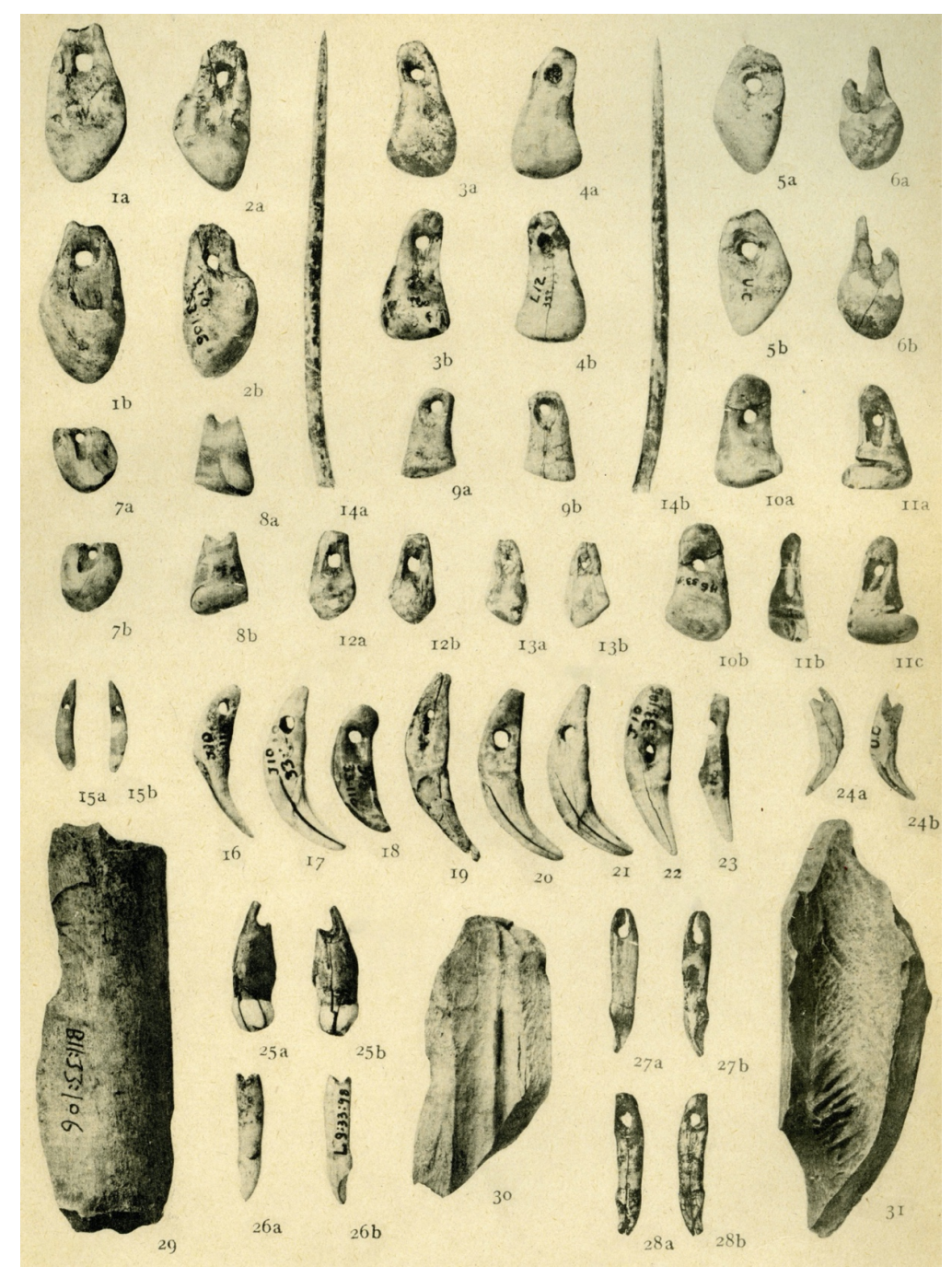

SOM Figure S6. Reproduction of Plate VII from Pei's (1939) monograph. Photographs of different aspects of perforated red deer canines (1-13), a bone eyed needle from layer L1 (14), a perforated decidual canine of a red deer (15), perforated fox canines (16-17, 19-21) badger canines (18, 22-23), marten canine (24), tiger incisor (25), Sika deer incisor (26-28), and two long bone diaphyses with flake scars (29-30). 


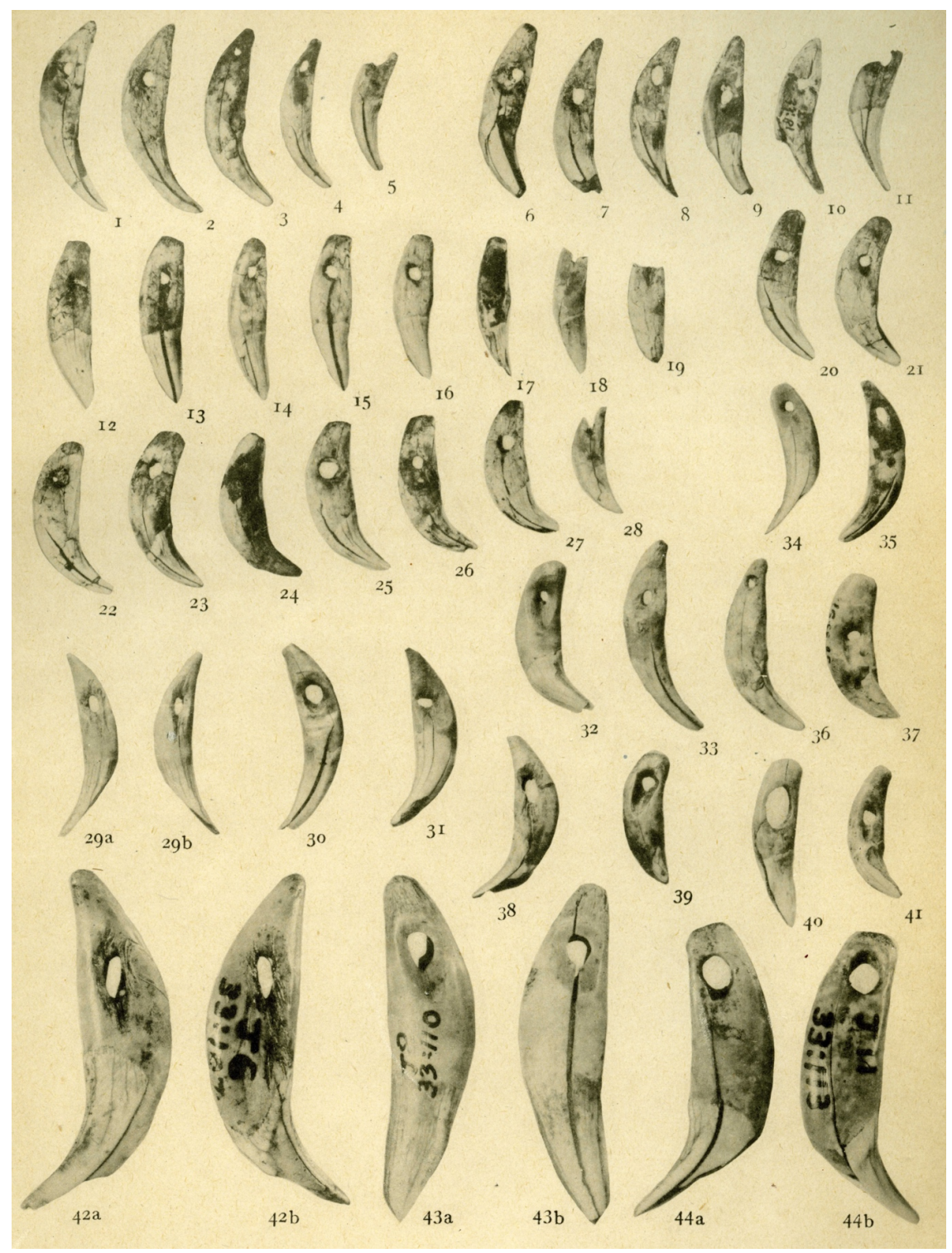

SOM Figure S7. Reproduction of Plate VIII from Pei's (1939) monograph. Photographs of different aspects of perforated fox canines $(1-11,29-31,33-36,38,42)$ and badger canines (12-28, 32, 37, 39-41, 43-44). 